\title{
Photocatalytic Degradation of Malachite Green Dye from Aqueous Solution Using Environmentally Compatible Ag/ZnO Polymeric Nanofibers
}

\author{
Marwa F. Elkady ${ }^{1,2, *}$ and Hassan Shokry Hassan ${ }^{3,4, *}$ \\ 1 Fabrication Technology Department, Advanced Technology and New Materials Researches Institute, \\ City of Scientific Researches and Technological Applications (SRTA-City), New Borg El-Arab City, \\ Alexandria 21934, Egypt \\ 2 Chemical and Petrochemical Engineering Department, Egypt-Japan University of Science and Technology, \\ New Borg El-Arab City, Alexandria 21934, Egypt \\ 3 Electronic Materials Researches Department, Advanced Technology and New Materials Researches Institute, \\ City of Scientific Researches and Technological Applications (SRTA-City), \\ New Borg El-Arab City, Alexandria 21934, Egypt \\ 4 Environmental Engineering Department, Egypt-Japan University of Science and Technology, \\ New Borg El-Arab City, Alexandria 21934, Egypt \\ * Correspondence: marwa.f.elkady@gmail.com (M.F.E.); hassan.shokry@gmail.com (H.S.H.); \\ Tel.: +20-122-720-9936 (M.F.E.); +20-128-230-5425 (H.S.H.)
}

check for updates

Citation: Elkady, M.F.; Hassan, H.S. Photocatalytic Degradation of Malachite Green Dye from Aqueous Solution Using Environmentally Compatible Ag/ZnO Polymeric Nanofibers. Polymers 2021, 13, 2033. https://doi.org/10.3390/polym13132033

Academic Editor: Mu Naushad

Received: 24 April 2021

Accepted: 2 June 2021

Published: 22 June 2021

Publisher's Note: MDPI stays neutral with regard to jurisdictional claims in published maps and institutional affiliations.

Copyright: (c) 2021 by the authors. Licensee MDPI, Basel, Switzerland. This article is an open access article distributed under the terms and conditions of the Creative Commons Attribution (CC BY) license (https:// creativecommons.org/licenses/by/ $4.0 /)$.

\begin{abstract}
An efficient, environmentally compatible and highly porous, silver surface-modified photocatalytic zinc oxide/cellulose acetate/ polypyrrole $\mathrm{ZnO} / \mathrm{CA} / \mathrm{Ppy}$ hybrid nanofibers matrix was fabricated using an electrospinning technique. Electrospinning parameters such as solution flow rate, applied voltage and the distance between needles to collector were optimized. The optimum homogenous and uniform $\mathrm{ZnO} / \mathrm{CA} / \mathrm{Ppy}$ polymeric composite nanofiber was fabricated through the dispersion of $0.05 \%$ wt $\mathrm{ZnO}$ into the dissolved hybrid polymeric solution with an average nanofiber diameter ranged between 125 and $170 \mathrm{~nm}$. The fabricated $\mathrm{ZnO}$-polymeric nanofiber was further surface-immobilized with silver nanoparticles to enhance its photocatalytic activity through the reduction of the nanofiber bandgap. A comparative study between $\mathrm{ZnO}$ polymeric nanofiber before and after silver immobilization was investigated using X-ray diffraction (XRD), scanning electron microscope (SEM), transmission electron microscopy (TEM), Fourier transform infrared (FTIR) and thermal gravimetric analysis (TGA). The photocatalytic degradation efficiency of the two different prepared nanofibers before and after nanosilver immobilization for malachite green (MG) dye was compared against various experimental parameters. The optimum degradation efficiency of nanosilver surface-modified $\mathrm{ZnO}$-polymeric nanofibers was recorded as $93.5 \%$ for malachite green dye after $1 \mathrm{~h}$ compared with $63 \%$ for $\mathrm{ZnO}$-polymeric nanofibers.
\end{abstract}

Keywords: photocatalytic; malachite green; wastewater remediation; $\mathrm{ZnO} / \mathrm{CA} / \mathrm{Ppy}$; composite nanofiber; silver immobilization

\section{Introduction}

The manufacturing of fabrics by textile industries has an abysmal impact on the environment due to the huge expending of synthetic dyes that improve the BOD and COD, impair photosynthesis, hinder plant growth, provide recalcitrance and promote carcinogenicity and mutagenicity [1,2]. Besides, insatiable consumption of water running to trillions of gallons per annum and large amounts of processed dye effluents containing thousands of tons of unconsumed dyes pose a great threat to ecology and the environment [3]. Despite stringent regulations imposed on the textile industries on wastewater treatment, the outcomes have been abysmally disappointing [4]. One of the major reasons is the absence of a sustainable remediation technique, method and/or procedure for 
the removal of toxic dyes. Sustainability as a system addresses the issues of economics, environment and social concern $[5,6]$.

Nanotechnology and Nanomaterials have the capability to secure sustainability in the field of industrial wastewater treatment through providing inventive technologies due to their ability to control the materials' functions and properties to be adequate with specific demand $[7,8]$.

Various techniques based on nanotechnology were reported in the literature for wastewater remediation, which may be broadly classified into four major categories including biological, chemical, physico-chemical and physical methods [9]. Most of these techniques are suffering from the main two limitations, which are the required remediation time for process completion and the sludge disposal after finishing the remediation process.

Photocatalytic degradation is a well-accepted favorable technique with great efficiency to completely degrade any organic compounds in the contaminated wastewater to convert them into harmless final products to human beings and the environment using a proper photocatalyst in presence of light radiation by producing highly reactive hydroxyl $(\mathrm{OH} \bullet)$ radicals, which can convert water pollutants into relatively unharmful end products like $\mathrm{CO}_{2}, \mathrm{H}_{2} \mathrm{O}$ and other inorganic ions $[10,11]$.

Photocatalytic technology has the ability to address the first problem concerned with remediation time with tangible solutions for the remediation of dyes from industrial effluents [12]. However, this technology still suffers from the problem of sludge disposal after the process's completion. Thus, it is ethically imperative to address the issue to provide a congenial solution for the disposal of sludge to guarantee the sustainability of photocatalytic technology [13]. One of the alternatives is to use eco-friendly compatible photocatalytic materials, which will have less impact on the environment and ecology.

A key parameter governing the performance of the photocatalytic materials is the generation of continuous electron reflux for producing highly reactive hydroxyl $(\mathrm{OH} \bullet)$ radicals responsible for dyes degradation at industrial effluents. A dangerous coloring cationic dye that requires degradation from polluted wastewater is malachite green dye (MG). This dye belongs to the triphenylmethane dyes category, which is heavily used in dye effluents and waste from industries like coloring materials, printing, leather, textiles, paper, plastic, pharmaceutical industries, medical laboratories and food industries [14]. This injurious dye can cause mutagenic, carcinogenic and teratogenicity effects to humans and animals due to the chemicals that are used to produce dyes are highly toxic, hormonal disruptors and carcinogens [15].

An efficient, environmentally compatible and highly porous photocatalytic hybrid nanofibers matrix can be fabricated simply by Electrospinning (ES) technique at low cost and high production rates. This hybrid nanofiber matrix offers outstanding photocatalytic characteristics to overcome the main two limitations stated previously at any photocatalytic degradation process which are the process operation time and the sludge produced. As the electrospun nanofibers have a very considerable surface area to magnitude proportion and high porosity that guarantee fast and high photo-degradation rate at short time intervals $[16,17]$. In order to solve the waste sludge problem, the materials utilized for nanofiber fabrication are suggested to be completely environmentally compatible for safe sludge disposal after finishing the remediation process $[18,19]$. The hybrid nanofiber matrix will be fabricated through the incorporation of zinc oxide $(\mathrm{ZnO})$ nanoparticle as a semiconductor filler onto the hybrid biocompatible polymeric matrix composed of cellulose acetate (CA) and polypyrrole (Ppy). As well-known, CA is renowned as a novel biomaterial and has broad industrial applications in its fibers form. Moreover, the CA fiber is described as relatively easy to manufacture, cost-economical, has good thermal stability, is a renewable natural resource of raw material, chemical-resistant and non-toxic $[20,21]$. Owing to the properties of Ppy as a conductive polymer in electron transfer procedure, it has been excessively utilized to excite a rapid photo-induced charge separation and comparatively slow charge recombination in photocatalytic processes including dye degradation in contaminated industrial wastewater [22]. Additionally, (ZnO) 
nanopowder is categorized as a semiconductor material with great importance for its versatile properties such as wide and direct fundamental energy band gap of $3.37 \mathrm{eV}$ and high exciting binding energy of $60 \mathrm{mV}$. $\mathrm{ZnO}$ is considered a highly stable, environmentally friendly and inexpensive material. Subsequently, it has potential applications in wastewater treatment domains, especially in the field of photocatalytic applications [23]. However, most metal oxides suffering from the problem of a recombination rate of the photogenerated electrons at their hole pairs during their operations as photocatalysts. Consequently, the incorporation of metal oxides with a noble metal such as silver nanoparticles represents the best scenario to overcome the electron recombination problem to improve the electron reflux available for the photocatalytic process. Accordingly, Ag nanoparticles will be immobilized on the surface of $\mathrm{ZnO}$ polymeric hybrid nanofibers to improve the photocatalytic efficiency of the fabricated $\mathrm{ZnO} / \mathrm{CA} /$ Ppy hybrid nanofiber and to act as electron sinks [24,25].

This work concerns the fabrication of efficient, environmentally compatible, photocatalytic, silver-immobilized $\mathrm{ZnO} / \mathrm{CA} /$ Ppy hybrid polymeric nanofibers using electrospinning technique and the assessment of the degradation efficiency of malachite green dye from simulated polluted wastewater in the presence of UV irradiation. In order to solve the sludge problem after the photocatalytic process, all constituents of the nanofiber were selected to be environmentally friendly materials. Moreover, the nano-ZnO utilized as filler at the hybrid nanofiber was green, synthesized using olive plant leaves extract to decrease the environmental impact of utilizing harmful chemicals. This fabricated eco-friendly hybrid nanofiber was assessed for the safe photocatalytic degradation of polluted dye to present a complete treatment of polluted industrial wastewater.

\section{Materials and Methods}

\subsection{Materials}

Olive plant leaves were collected from New Borg El-Arab City, Alexandria, Egypt for the biosynthesis of $\mathrm{ZnO}$ nanoparticles. Most of the utilized other chemicals were of analytical grade with high purity including zinc nitrate hydrate $(99.999 \%$, Sigma-Aldrich, St. Louis, MO, USA), cellulose acetate (CA) (MW 30000, Sigma-Aldrich, St. Louis, MO, USA), acetic acid (99.8\%, Alfa Aser, Haverhill, MA, USA), acetone (99.5\%, Sigma-Aldrich, St. Louis, MO, USA), N, N-dimethyl-formamide (DMF) (99.8\%, Across Organics, Fair Lawn, NJ, USA), malachite green dye (MG) (purity 99.9\%, Sigma-Aldrich, St. Louis, MO, USA), silver nitrate (99\%, Sigma-Aldrich, St. Louis, MO, USA), pyrrole ( $99.5 \%$, SigmaAldrich, St. Louis, MO, USA), ferric chloride ( $99.9 \%$, Across Organics, Fair Lawn, NJ, USA), sodium hydroxide and hydrochloric acid $(99.8 \%$, Sigma-Aldrich, St. Louis, MO, USA). Freshly distilled water was used for the preparations of all aqueous solutions and washing purposes.

\subsection{Methods}

\subsubsection{Green Synthesis of $\mathrm{ZnO}$ Nanoparticles as Filler}

Zinc nitrate salt $\left(\mathrm{Zn}\left(\mathrm{NO}_{3}\right)_{2} 6 \mathrm{H}_{2} \mathrm{O}\right)$ of $0.2 \mathrm{M}$ was reduced with $30 \mathrm{~mL}$ of olive plant leaves extract. The extract was produced after grinding the olive plant leaves that were soaked in distilled water under vigorous stirring for $1 \mathrm{~h}$ at $40^{\circ} \mathrm{C}$. This extract was added to zinc nitrate salt dropwise under constant stirring at $60^{\circ} \mathrm{C}$ for $1 \mathrm{~h}$. The produced $\mathrm{ZnO}$ nanopowder materials were dried at $100^{\circ} \mathrm{C}$ overnight. During the drying process, complete conversion of zinc hydroxide into zinc oxide takes place until its color is converted into a sunny white color [7].

\subsubsection{Synthesis of Polypyrrole (Ppy) Nanoparticles}

Ppy nanopowder was synthesized using the chemical oxidation polymerization technique. $120 \mathrm{~mL}$ of $0.2 \mathrm{M}$ ferric chloride was used as an oxidant under continuous stirring for $30 \mathrm{~min}$. Then, $2 \mathrm{~mL}$ pyrrole monomer was added dropwise under continuous stirring for $2 \mathrm{~h}$; the addition was performed slowly at a low temperature around $2-7^{\circ} \mathrm{C}$ using an ice bath. The produced Ppy suspension was kept for $24 \mathrm{~h}$ in the dark to complete the 
polymerization process. The formed black precipitate of Ppy was filtered and washed several times with ethanol and distilled water to remove the unreacted pyrrole and excess of ferric chloride and any impurities present. A final black precipitate of Ppy was obtained after $12 \mathrm{~h}$ of vacuum drying at $30-40{ }^{\circ} \mathrm{C}$.

\subsection{Fabrication of $\mathrm{ZnO}$ Polymeric Composite Nanofiber}

Preparation of ZnO Nanoparticles as Filler into the Polymeric Composite Solution

Ppy nanopowder was dissolved in DMF/acetone mixed solvent with a ratio of 6:7 and $\mathrm{ZnO}$ nanoparticle was dispersed at the dissolved polypyrrole solution. DMF was mixed with acetone to delay the evaporation of acetone during electrospinning to form a uniform nanofiber. In order to prepare a homogeneous solution, this suspension was sonicated for $5 \mathrm{~min}$ then stirred using a magnetic stirrer at $300 \mathrm{rpm}$ for $24 \mathrm{~h}$. After obtaining a homogeneous suspension from $\mathrm{ZnO}$ nanoparticle dispersed into Ppy, add a certain amount of cellulose acetate powder to this suspension then further sonicate for $15 \mathrm{~min}$ and stir using a magnetic stirrer at $300 \mathrm{rpm}$ for another $24 \mathrm{~h}$ until the formation of a homogeneous solution through the generation of a clear colloidal solution that is ready for the electrospinning process [26].

\subsection{Electrospinning of $\mathrm{ZnO}$ Polymeric Composite Nanofiber}

The solution contained a certain amount of dissolved CA and Ppy composite polymers in DMF: acetone 6:7 mixed solvent and $0.1 \mathrm{~g}$ of dispersed $\mathrm{ZnO}$ nanopowder as filler. This homogeneous suspension was loaded into a syringe $(5 \mathrm{~mL})$ with a stainless-steel needle to start the electrospinning process. The concentration of CA polymer was varied between ( 8 and $16 \mathrm{wt} \%$ ) at a fixed weight from Ppy $(0.3 \mathrm{~g})$. The electrospinning parameters such as applied electrical voltage $(8-30 \mathrm{kV})$, the distance between the tip of the syringe needle and collector $(8-20 \mathrm{~cm})$, feed solution flow rate $(0.2-1 \mathrm{~mL} / \mathrm{h})$ and the amount of loaded $\mathrm{ZnO}$ nanopowder as filler into the polymeric composite mixture at room temperature $\left(15 \pm 30^{\circ} \mathrm{C}\right)$ were optimized to fabricate uniform composite nanofiber.

\subsection{Surface Modification of $\mathrm{ZnO}$ Polymeric Composite Nanofiber by Silver Immobilization}

In order to reduce the bandgap of fabricated $\mathrm{ZnO}$ polymeric composite nanofiber to enhance its photocatalytic activity, silver was immobilized onto the fiber surface through the following surface modification process. A small piece of the fabricated $\mathrm{ZnO}$ polymeric composite nanofiber with dimensions of $1 \times 1 \mathrm{~cm}$ was immersed in $100 \mathrm{~mL}$ of silver nitrate $(0.85 \mathrm{~g})$ solution mixed with the aqueous extract of olive leaves. The nanofiber was maintained socked at the solution under gentle stirring using an orbital shaker until the reduction process of silver was completed. The small piece of surface-modified $\mathrm{Ag} / \mathrm{ZnO}$ polymeric composite nanofiber small was washed 5 times with distilled water to remove any residuals then dried at $40-50{ }^{\circ} \mathrm{C}$ for $8 \mathrm{~h}$.

\subsection{Characterization of $\mathrm{ZnO}$ Polymeric Composite Nanofibers before and after Silver Immobilization}

XRD patterns of $\mathrm{ZnO}$ polymeric nanofibers before and after silver immobilization were obtained using Schimadzu7000 (Schimadzu, Kyoto, Japan) diffraction operating with $\mathrm{Cu} \mathrm{K} \alpha$ radiation $(\lambda=0.15406 \mathrm{~nm})$, generated at $30 \mathrm{kV}$ and $30 \mathrm{~mA}$ with a scan rate of $2 \mathrm{~min}^{-1}$ for $2 \theta$ values between 10 and 80 degrees. Scanning electron microscope (SEM) analysis JEOL JSM 6360LA (Akishima, Tokyo, Japan) was performed to determine the shape, size and morphology of $\mathrm{ZnO}$ polymeric composite nanofibers. The uniformity and homogeneity of the two prepared $\mathrm{ZnO}$ polymeric composite nanofibers before and after silver immobilization was confirmed using TEM JEOL JEM 1230 (Akishima, Tokyo, Japan) and the percentage of silver element immobilization was confirmed using the EDX analysis combined with the equipment of the FTIR spectrum of $\mathrm{ZnO}$ nanofibers before and after silver immobilization was established using Shimadzu FTIR-8400 S (Schimadzu, Kyoto, Japan) at a wavelength range of $400-4000 \mathrm{~cm}^{-1}$. The thermal stability of $\mathrm{ZnO}$ 
nanofibers before and after silver immobilization was evaluated by TGA Shimadzu TGA$50 \mathrm{H}$ (Schimadzu, Kyoto, Japan).

\subsection{Photocatalytic Degradation of Malachite Green Dye Using Various Fabricated ZnO Polymeric Composite Nanofibers}

The photocatalytic degradation of malachite green (MG) dye was carried out by contacting $25 \mathrm{~mL}$ of $10 \mathrm{ppm}$ dye solution in a $100 \mathrm{~mL}$ round flask with $0.05 \mathrm{~g}$ from either $\mathrm{ZnO}$ polymeric composite nanofibers before or after silver surface immobilization. The solution was exposed to Xenon lamp $500 \mathrm{~W}$ (Alexandria City, Egypt) for certain time intervals under continuous stirring. The dye solution sample was withdrawn for analysis using UV spectrophotometer every 10 min during the irradiation process to determine the MG dye degradation efficiency which appears in the visible region that was measured at $624 \mathrm{~nm}$.

The decolorization efficiency of MG dye through the photocatalytic process was calculated by the following formula:

$$
\text { Efficiency } \%=\left(C_{o}-C\right) / C_{o} \times 100
$$

The concentrations of primal and decomposed dye solution are $C_{o}$ and $C$, respectively. The same experimental procedure was followed to elucidate the influence of various photodegradation parameters including contact time (0-100 min.), catalyst dosage $(0.05-0.25 \mathrm{~g})$, initial dye concentrations (10-100 ppm), solution $\mathrm{pH}(2-12)$ and temperature $\left(25-80{ }^{\circ} \mathrm{C}\right)$ on the MG dye-decolorization process. Each experiment was repeated in triplicate manner and the mean results were utilized in data analysis.

Finally, the experimental data from these studied parameters that were either recorded at the equilibrium time or over the studied time intervals were theoretically modeled to determine the suitable models describing the malachite green dye photocatalytic degradation process on the two prepared $\mathrm{ZnO}$ polymeric composite nanofibers before and after $\mathrm{Ag}$ surface immobilization.

\subsection{Reusability of Fabricated $\mathrm{ZnO}$ Polymeric Composite Nanofibers}

In order to improve the economic feasibility of the photocatalytic process using the prepared $\mathrm{ZnO}$ polymeric composite nanofibers before and after silver immobilization, the spent $\mathrm{ZnO}$ polymeric composites nanofibers after the photocatalytic process were regenerated through three times rinsing with $0.2 \mathrm{~mol} / \mathrm{L} \mathrm{HCl}$ solution followed by deionized water then dried at $50{ }^{\circ} \mathrm{C}$ overnight for further reuse.

\section{Results}

\subsection{Optimization of the Fabrication of $\mathrm{ZnO}$ Polymeric Composite Nanofibers}

Nanofibers' diameters and their homogeneity could be enhanced by changing the different parameters during the electrospinning process such as the cellulose acetate polymer solution concentration, flow rate, electrical applied voltage, distances between the syringe needle tip and the collector and the amount of loaded $\mathrm{ZnO}$ nanopowder as filler.

The morphological structure of nanofibers produced at the three studied cellulose acetate (A1-A3) polymer concentrations at a constant flow rate of $0.2 \mathrm{~mL} / \mathrm{h}$, an applied voltage of $20 \mathrm{kV}$ and the distance between needle tip to the collector of $12 \mathrm{~cm}$ was investigated at Figure 1A. It is clear that no continuous fiber was formed at $8 \mathrm{wt} \%$ polymer concentration (A1) and only electrospray and droplets from the polymer solution were collected on the foil (collector). As the CA polymer concentration improved from $12 \mathrm{wt} \%$ (A2) to $16 \mathrm{wt} \%$ (A3), continuous and thick fibers were obtained with the appearance of some beads. These beads disappeared with increasing CA concentration due to the improvement of electrospun solution viscosity as indicated for SEM image for sample (A3) from Figure 1(A1). On the other hand, as evident from Figure 1(A1), the increment in polymer concentration from $12 \%$ to $16 \%$ tends to decrease the fiber diameter [27]. Accordingly, the CA polymer 
concentration of $16 \%$ was selected as the optimum concentration for further optimization of the remaining electrospinning parameters [28].

The nanofibers morphology can be also adapted by changing the flow rate of electrospun $16 \%$ CA solution overstudied range $(0.2-1 \mathrm{~mL} / \mathrm{h})$ with the same previously stated electrospinning parameters $(20 \mathrm{kV}$ applied voltage and $12 \mathrm{~cm}$ distance between needle tip to the collector). The SEM images of the different produced nanofibers shown in Figure 1(B1) observed that as the flow rate increased, the thickness of produce fibers was increased with the appearance of some droplets. This result may be attributed to the improvement in the solution flow rate, which delivers more polymeric composite solution to the nanofiber sheet, which increases the diameter of the liquid faucet and subsequently, the creation of thicker nanofibers [29]. Therefore, $0.2 \mathrm{~mL} / \mathrm{h}$ was considered as the optimum flow rate for spinning $16 \%$ CA solution.

Another important factor in the fabrication of uniform electrospun nanofibers is the applied electrical voltage between the needle tip and collector. Three different electrical voltages $(10,18,30 \mathrm{kV})$ were applied for electrospun $16 \%$ CA solution at the pre-optimized electrospinning conditions $(0.2 \mathrm{~mL} / \mathrm{h}$ flow rate and $12 \mathrm{~cm}$ distance between needle tip to the collector). The micrographs of the three different fabricated nanofibers at studied electrical voltages were illustrated in Figure 1(C1). It was indicated that the increment of applied voltage from 10 to $30 \mathrm{kV}$ has a positive impact on decreasing the fiber diameter. This is due to the increase of the applied voltage, which enhances the magnitude of the electric field and results in a thinner liquid jet. Therefore, the optimum applied voltage was selected as $18 \mathrm{kV}$.

Three various distances of 8,12 and $18 \mathrm{~cm}$ between the needle tip and collector were studied at a constant CA polymer concentration of $16 \%$, at a spinning flow rate of $0.2 \mathrm{~mL} / \mathrm{h}$ and $18 \mathrm{kV}$ applied voltage [29]. The SEM images and the corresponding diameter dependence on distance are shown in Figure 1(D1). The distance from the needle tip to the collector has to be set to a golden distance to produce thinner fibers because any distance below or above this golden distance will result in larger fiber diameter. This is because, if the distance is too short, the fibers will not have enough time to dry and the fiber diameter increased. However, when the distance is too long, the effect of voltage on the liquid jet will be small, and hence results in much thicker fibers. In this investigation, it was observed that $18 \mathrm{~cm}$ is such a golden distance to produce good fibers and it was selected as the optimum distance.

Finally, the amount of $\mathrm{ZnO}$ NPs as filler to enhance the photocatalytic activity of nanofiber was optimized at the pre-optimized electrospinning conditions of nanofibers $(0.2 \mathrm{~mL} / \mathrm{h}$ solution flow rate, applied voltage $18 \mathrm{kV}$, polymer concentration $16 \%$ and distance between needle tip to the collector was set at $18 \mathrm{~cm}$ ). The four different $\mathrm{ZnO}$ polymeric composite nanofibers at various filler amounts of 0.02, 0.05, 0.07, $0.1 \mathrm{wt} \%$ are imaged in Figure 1(E1). It was indicated from SEM images that the sample loaded with smaller $\mathrm{ZnO}$ filler $(0.02 \%)$ showed homogeneous and uniform nanofibers without any beads but with a large fiber diameter range. As the amount of dispersed $\mathrm{ZnO}$ filler increased up to $0.05 \%$, the diameter of produced fiber was decreased. This may be due to the properties of the semiconductors of immobilized $\mathrm{ZnO}$ that enhance the spinning properties of composite nanofiber. However, as the filler amount improved above $0.05 \%$, the fiber diameter was increased and the beaded fiber was produced, owing to the formation of $\mathrm{ZnO}$ aggregates that hinder the spinning process and decrease the chance for the production of homogeneous nanofibers at higher $\mathrm{ZnO}$ filler concentrations [29,30]. Accordingly, $0.05 \%$ nano- $\mathrm{ZnO}$ was selected as the most proper filler concentration for the fabrication of a homogeneous and uniform $\mathrm{ZnO}$ polymeric composite nanofibers matrix with good porosity, as evident from the optical image of the matrix (Figure 1) with the average fiber diameter ranged between 125 and $170 \mathrm{~nm}$. 
(A)

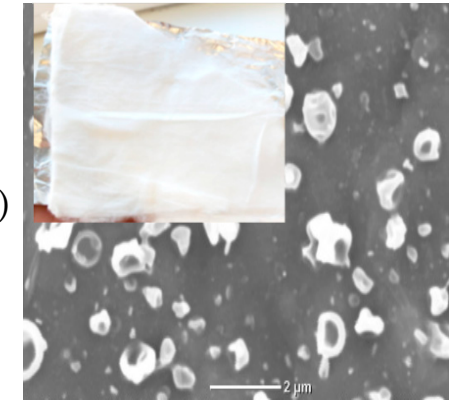

A1

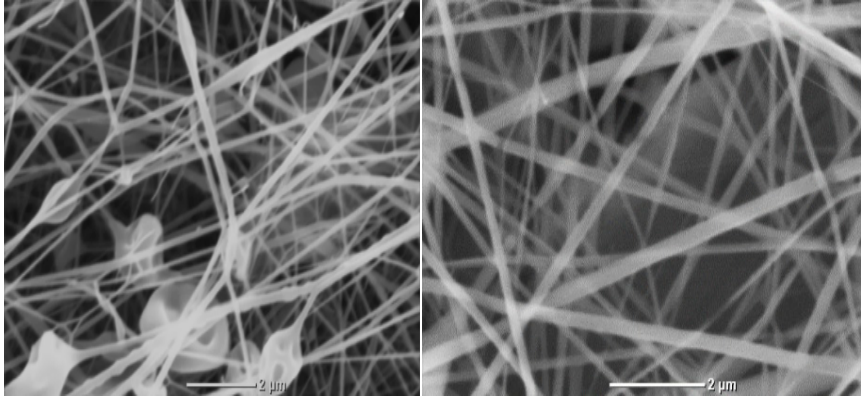

A2

A3

(B)

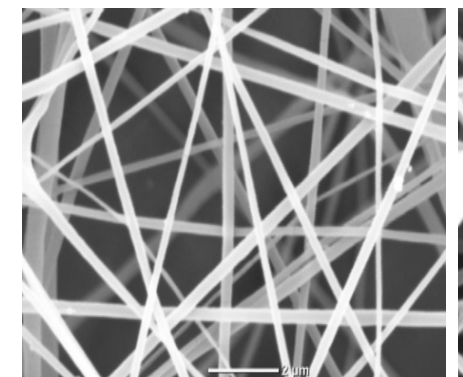

B1

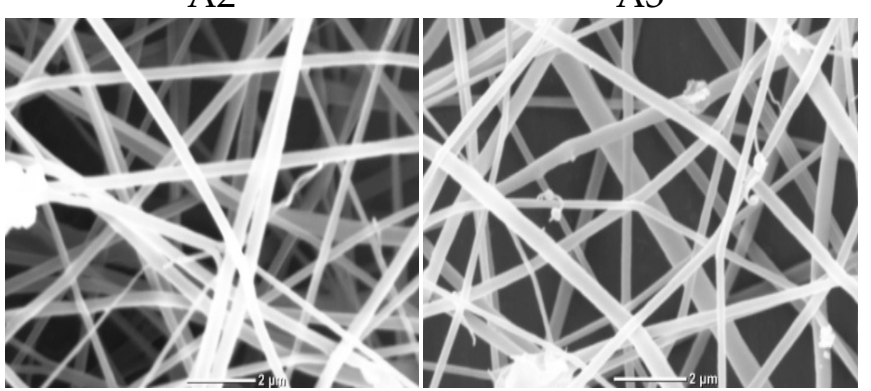

(C)

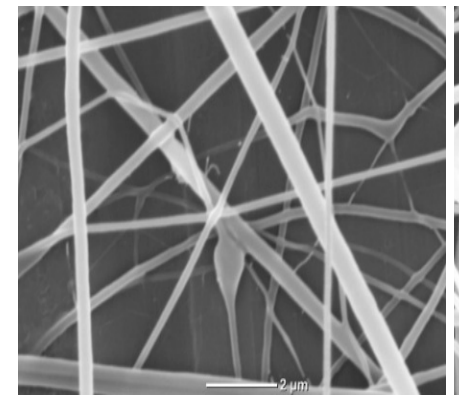

B2

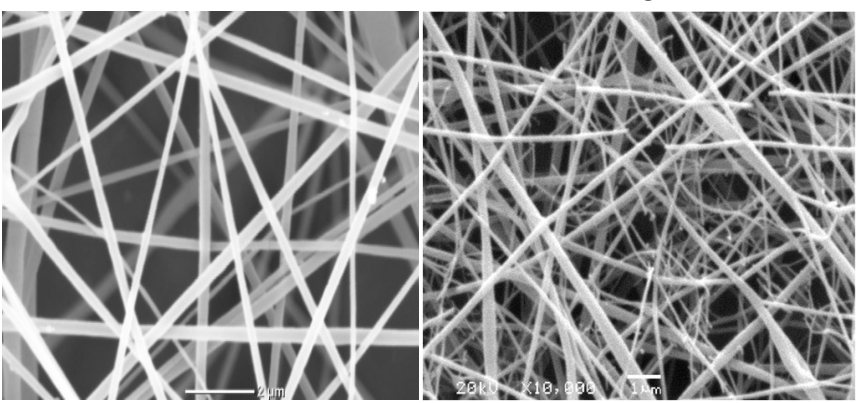

(D)

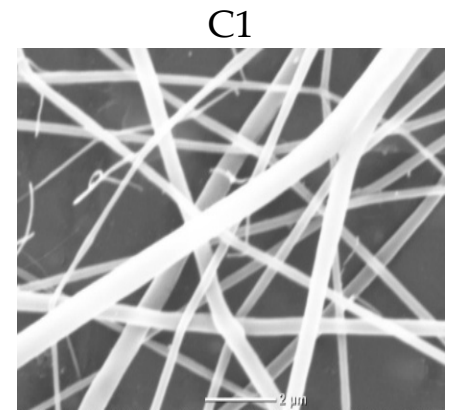

D1

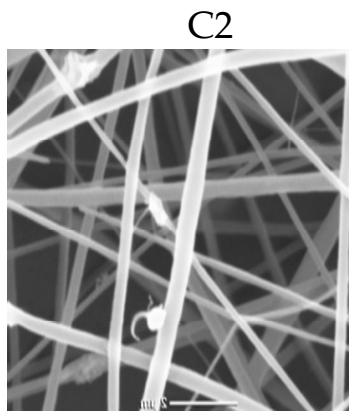

D2
C3

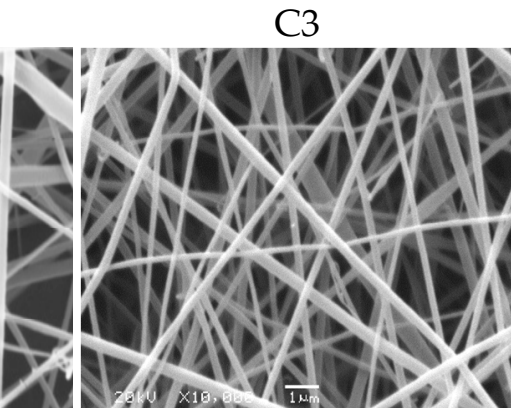

D3

(E)

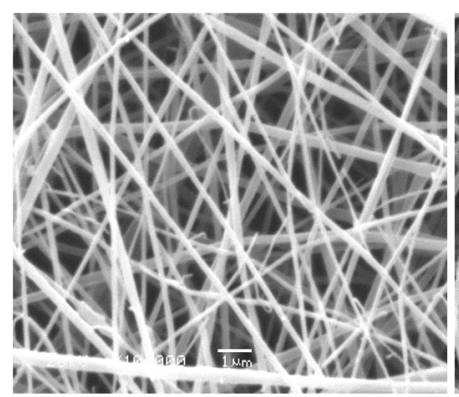

E1

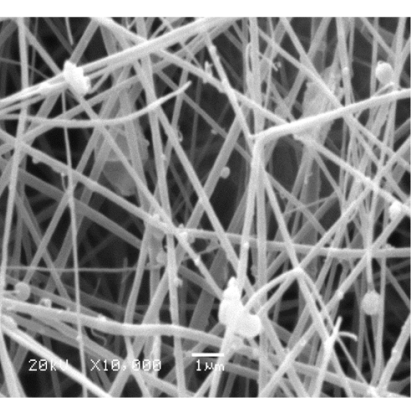

E2

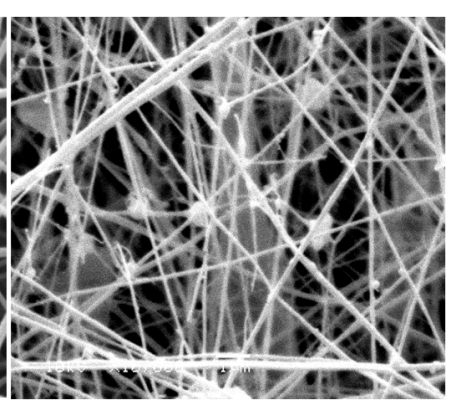

E3

Figure 1. SEM micrographs of electrospinning processing parameters on fabricated $\mathrm{ZnO}$ polymeric composite nanofiber: (A) Cellulose acetate concentration (8-16 wt\%), (B) solution flow rate $(0.2-1 \mathrm{~mL} / \mathrm{h}$ ), (C) applied voltage (10-30 KV), (D) distance between needle tip and collector $(8-18 \mathrm{~cm})$ and (E) amount of loaded ZnO NPs as a filler $(0.02-0.1 w t \%)$. 


\subsection{Silver Immobilization onto $\mathrm{ZnO}$ Polymeric Composite Nanofibers for Enhancing Photocatalytic Activity}

In order to improve the photocatalytic activity of fabricated $\mathrm{ZnO}$ polymeric composite nanofibers, it was surface-immobilized with Ag to decrease the fiber bandgap and subsequently improve its photocatalytic efficiency. This is mainly due to increased chargetransfer capacity by lowering bandgap energy; there was a minimized recombination of the excited electron-hole pairs of $\mathrm{ZnO}$ with the addition of $\mathrm{Ag}$ into the $\mathrm{ZnO}$ crystal lattice [31]. TEM images of $\mathrm{ZnO}$ polymeric nanofibers before (A) and after (B) silver immobilization are compared in Figure 2. In the case of $\mathrm{ZnO}$ polymeric nanofibers before Ag immobilization, a TEM image showed the homogeneous distribution of $\mathrm{ZnO}$ nanoparticles all over the fabricated nanofibers, while in the case of $\mathrm{ZnO}$ polymeric nanofibers after $\mathrm{Ag}$ immobilization, much higher intensity surface-immobilized nanoparticles were noticed that corresponded to Ag nanoparticles localized at the surface of the nanofibers. Moreover, dark agglomerated particles appeared for Ag-immobilized nanofiber; this may be due to the surface deposition of $\mathrm{Ag}$ nanoparticles onto $\mathrm{ZnO}$ nanoparticles loaded onto polymeric nanofiber that appeared as dark agglomerated spots.

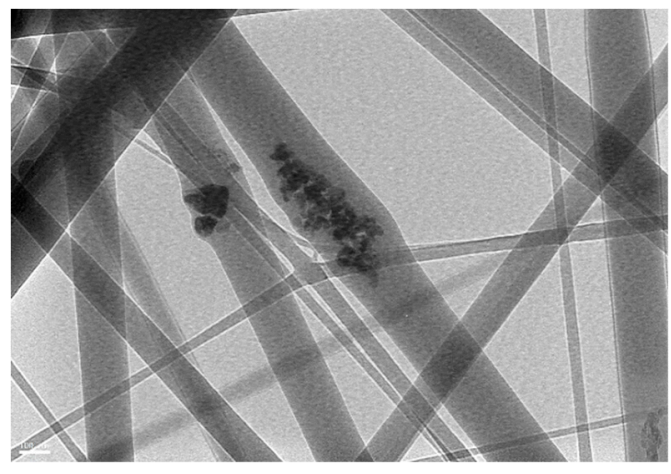

(A)

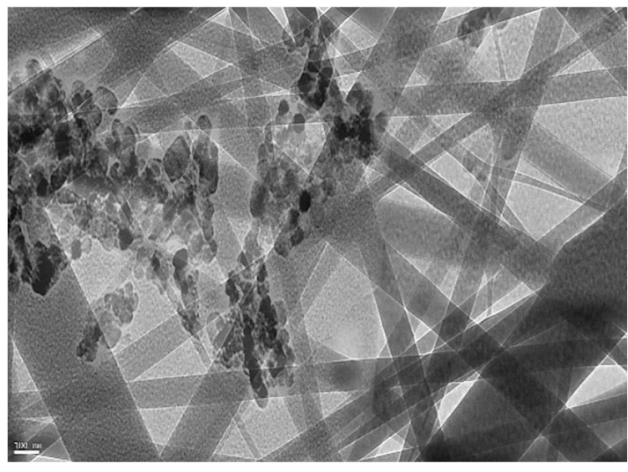

(B)

Figure 2. TEM micrographs of ZnO polymeric composite nanofiber (A) before silver immobilization and (B) after silver immobilization.

3.3. Comparable Investigation of the Prepared $\mathrm{ZnO}$ Polymeric Composite Nanofibers before and after Silver Immobilization

3.3.1. X-ray Diffraction Patterns (XRD)

In order to confirm the fabrication of $\mathrm{ZnO}$ polymeric composite nanofiber before and after silver immobilization, XRD patterns of various prepared materials including $\mathrm{ZnO}$ NPs, Ppy NPs and ZnO polymeric nanofibers after and before Ag immobilization were compared. Figure 3A showed the XRD pattern of ZnO NP synthesized using plant leaves extract; the pattern confirmed that the prepared material of wurtzite hexagonal structure and has a high crystalline degree. It indicated that distinctive peaks appeared at 31.7 (100), 34.4 (002), 36.2 (101), 47.5 (102), 56.6 (110), 62.8 (103), 67.9 (112) and 69.1 (201). This result is in perfect agreement with wurtzite ZnO (JCPDS ZnO Card No: 36_1451). The average particle size of ZnO NPs was calculated using the Scherrer equation that considers its nano-size range from 8.5 to $13 \mathrm{~nm}$ [32].

$\mathrm{X}$-ray diffraction pattern of $\mathrm{ZnO}$ polymeric composite nanofibers investigated three sets of different diffraction peaks that corresponding to cellulose acetate, $\mathrm{ZnO}$ and Ppy. Figure $3 \mathrm{C}$ shows characteristic peaks for the wurtzite structure of $\mathrm{ZnO}$ at $2 \theta$ region of $31.7^{\circ}(100), 34.4^{\circ}(002), 36.2^{\circ}(101), 47.5^{\circ}(102), 56.6^{\circ}(110), 62.8^{\circ}(103), 67.9^{\circ}(112)$ and $69.1^{\circ}$ (201) in addition to cellulose acetate, which is well-defined at the crystalline peaks at $2 \theta$ equals to $13.83^{\circ}$ and $16.63^{\circ}$ which verified its crystalline nature. Finally, the broad peaks at $2 \theta$ of $18^{\circ}-30^{\circ}$, revealing the presence of amorphous Ppy. This XRD pattern confirms the successful fabrication of $\mathrm{ZnO}$ polymeric composite nanofiber. 


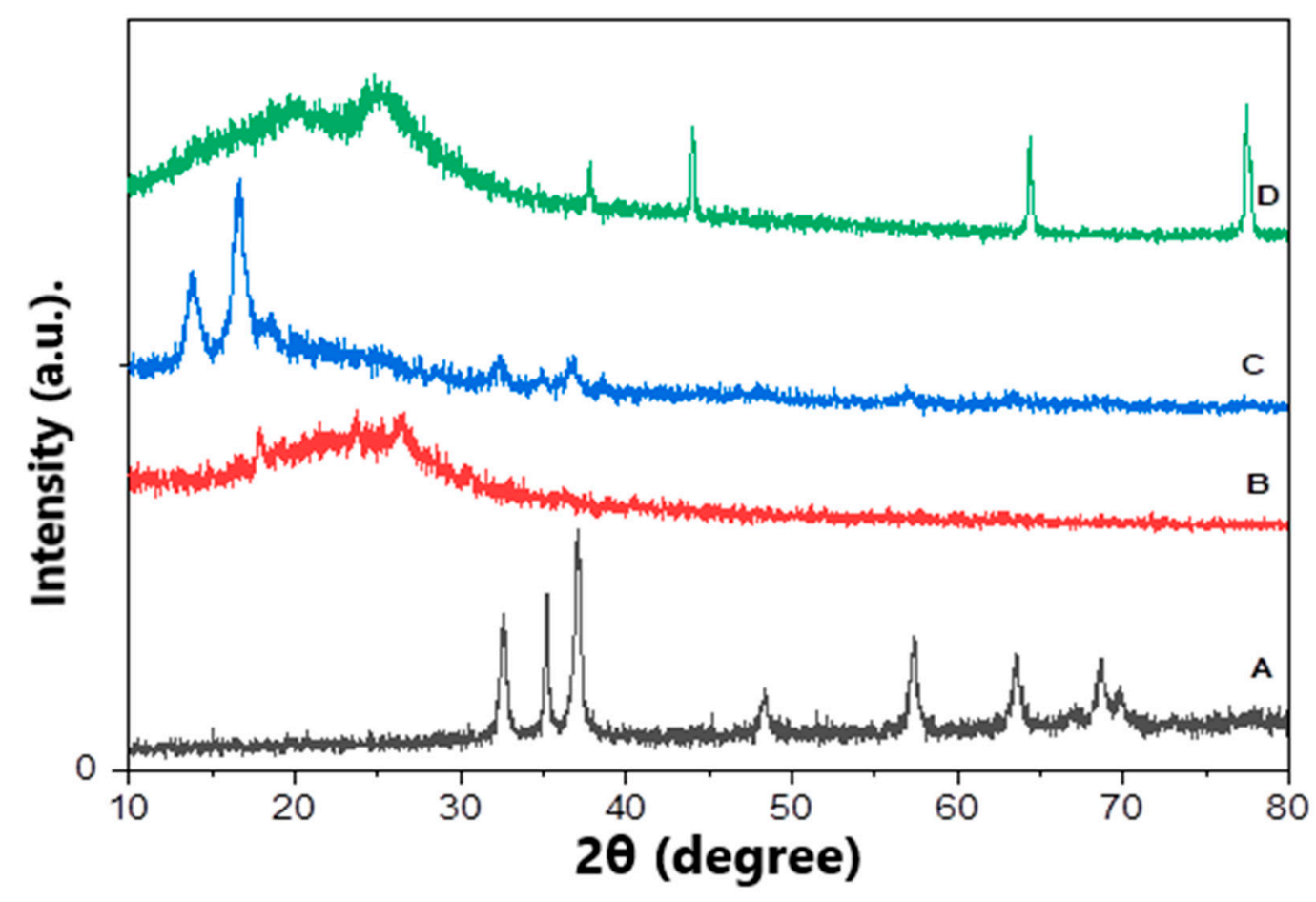

Figure 3. XRD patterns of various prepared matrices, (A) ZnO NPs, (B) Ppy NPs, (C) ZnO polymeric composite nanofibers and (D) $\mathrm{ZnO}$ polymeric composite nanofibers after silver immobilization.

The XRD pattern of Ppy NPs synthesized via chemical oxidation polymerization illustrated in Figure 3B shows the broad peaks at the $2 \theta$ region $18-30^{\circ}$, revealing the amorphous nature of prepared Ppy NPs [33,34].

Regarding $\mathrm{ZnO}$ polymeric composite nanofiber after silver surface modification, the XRD pattern illustrated in Figure 3D showed most of the previously characteristic peaks of $\mathrm{ZnO}$, Ppy and cellulose acetate with a reduction in peaks intensity. However, new peaks were illustrated at $37.8(111), 43.8$ (200) and 77.2 (311), corresponding to silver immobilized on the nanofiber surface $[35,36]$. The percentage of immobilized silver was detected using EDX analysis of $\mathrm{ZnO}$ polymeric composite nanofiber after silver immobilization; it was indicated that the weight $\%$ of the fiber analysis was oxygen 59.43 , carbon 23.92 , zinc 14.6 and silver 2.05. Accordingly, silver was immobilized, with around $2 \%$ by weight from the fabricated $\mathrm{ZnO}$ polymeric composite nanofibers.

\subsubsection{FTIR-Spectrophotometric Analysis}

FTIR spectrums of the polymeric composite nanofiber before and after silver immobilization are illustrated in Figure 4A,B; both spectrums showed stretching peaks for N-H and C-H deformation vibration that were located at $1026 \mathrm{~cm}^{-1}$ and $1051 \mathrm{~cm}^{-1}$, respectively. The peaks at wavenumbers of $1051 \mathrm{~cm}^{-1}, 1730 \mathrm{~cm}^{-1}, 1735 \mathrm{~cm}^{-1}$ and $2947 \mathrm{~cm}^{-1}$ were attributed to $\mathrm{O}-\mathrm{CH}_{3}$ stretching, $\mathrm{C}=\mathrm{O}$ stretching, $\mathrm{CH}_{3}$ stretching and $\mathrm{CH}$ stretching vibrations, respectively.

A wide-range absorption band at $3483 \mathrm{~cm}^{-1}$ corresponding to $\mathrm{N}-\mathrm{H}$ ring vibrations of polypyrrole at the composite nanofiber matrices was investigated. The characteristic bands in the range of $400-600 \mathrm{~cm}^{-1}$ are attributed to $\mathrm{Zn}-\mathrm{O}$ stretching of $\mathrm{ZnO}$ material. These two FTIR spectrums confirm the fabrication of $\mathrm{ZnO}$ polymeric composite nanofibers. Comparing the two FTIR spectrums, it is clear that the silver surface-immobilized $\mathrm{ZnO}$ polymeric composite nanofiber characteristics by new peaks that appeared at 3483, 1739, 1535,462 and $1404 \mathrm{~cm}^{-1}$. These new absorbance bands were attributed to the stretching vibrations of primary and secondary amines groups that confirm the presence of plant leaves extract used for the green synthesis of $\mathrm{Ag}$ on the nanofiber surface. Moreover, the characteristic peak, appearing in the range of $3300-3500 \mathrm{~cm}^{-1}$, was broader at Ag 
immobilized nanofiber compared with the nanofiber before Ag immobilization; this may have originated from polyphenols stretching of the $\mathrm{OH}$ group that are present in the leaves extract after silver immobilization [20,37].

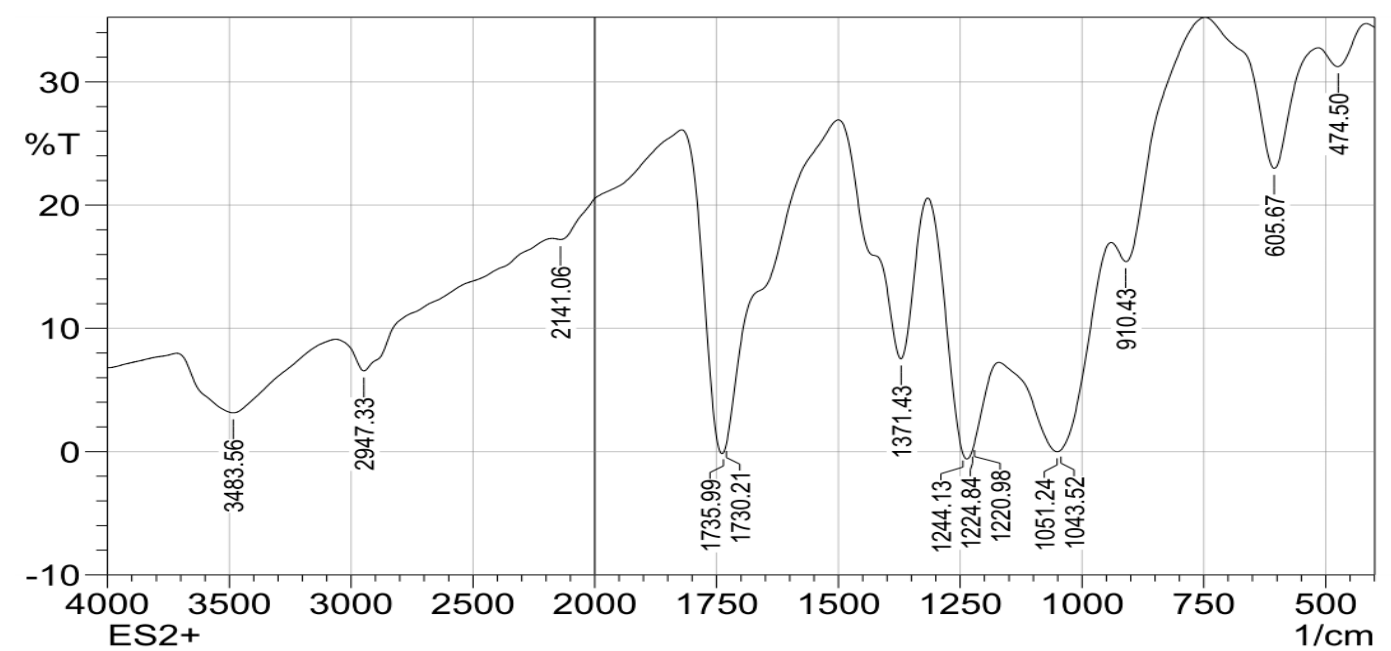

(A)

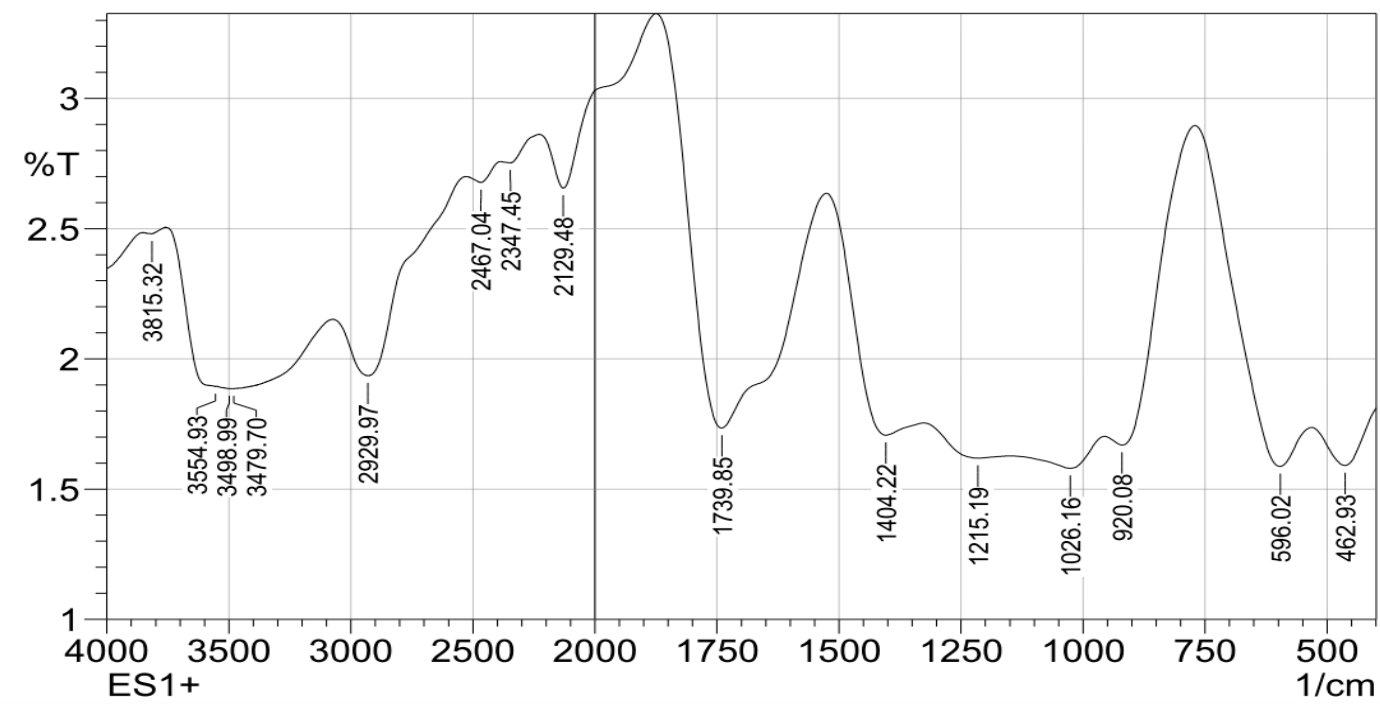

(B)

Figure 4. FTIR spectrophotometric analysis for ZnO polymeric composite nanofiber (A) before silver immobilization and (B) after silver immobilization.

\subsubsection{Thermo-Gravimetric Analysis (TGA)}

Figure 5A,B showed typical TGA analysis for $\mathrm{ZnO}$ polymeric composite nanofibers before and after silver immobilization.

For comparative purposes, the two TGA patterns showed almost the same multistage degradation steps. Both patterns showed slight mass losses of $\sim 5 \%$ up to $250{ }^{\circ} \mathrm{C}$, corresponding to the loss of volatile compounds and physically and chemically adsorbed water molecules bound to the hydrophilic $(\mathrm{OH})$ groups of the cellulose acetate chains. These mass losses were followed by two more stages of thermal decomposition for the two patterns. The first step was between 250 and $410{ }^{\circ} \mathrm{C}$, with mass losses ranged from $\sim 70$ to $75 \%$ for the two samples. This degradation step corresponds to the main thermal decomposition event and can be attributed to cellulose acetate chain degradation due to the breakdown of glycosidic bonds followed by the primary decomposition in volatile and 
dehydrated compounds. This degradation step was followed by the second degradation step between 410 and $500{ }^{\circ} \mathrm{C}$, corresponding with nanofiber matrix carbonization, resulting in the complete degradation and decomposition of the polymeric matrix. This last step of thermal degradation highlighted the role of the presence of Ag surface immobilization in enhancing the thermal degradation performance of the $\mathrm{ZnO}$ polymeric composite nanofibers matrix [21].

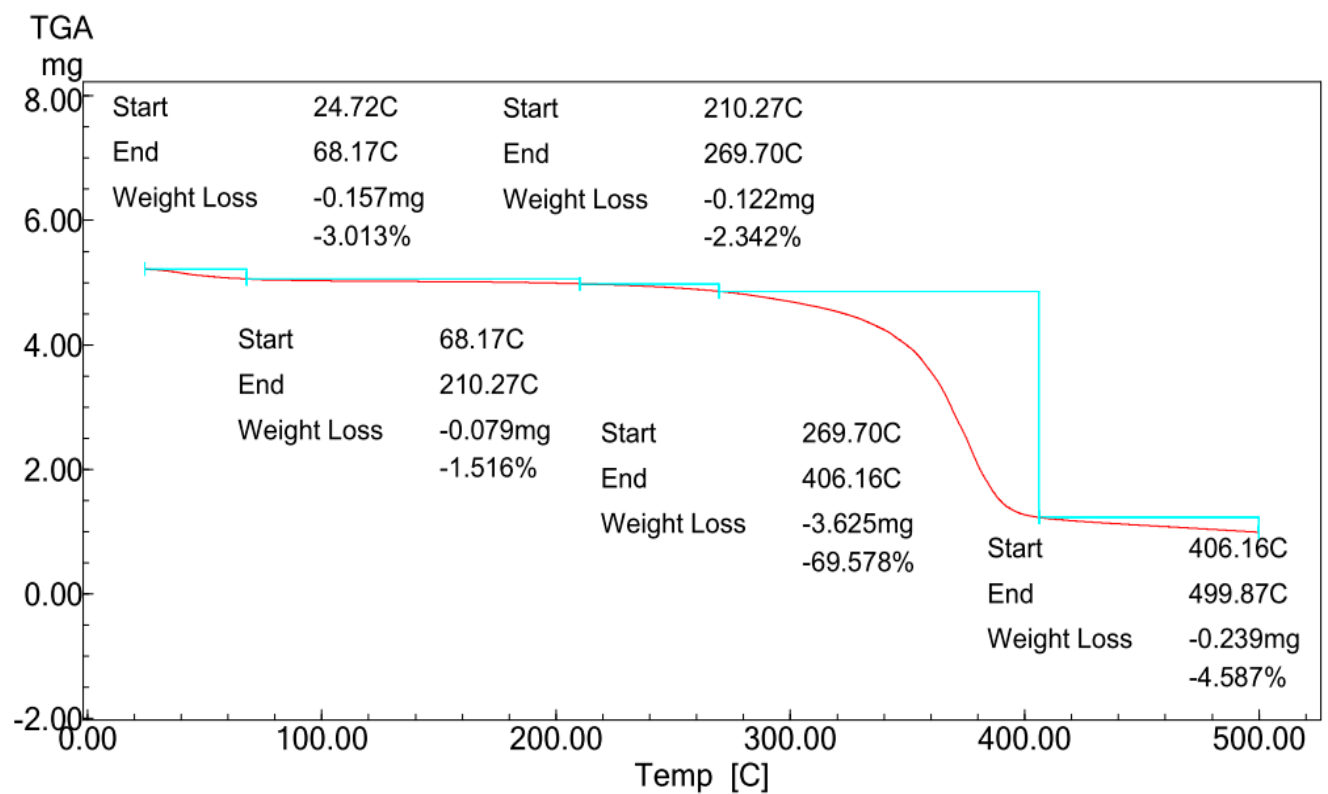

(A)

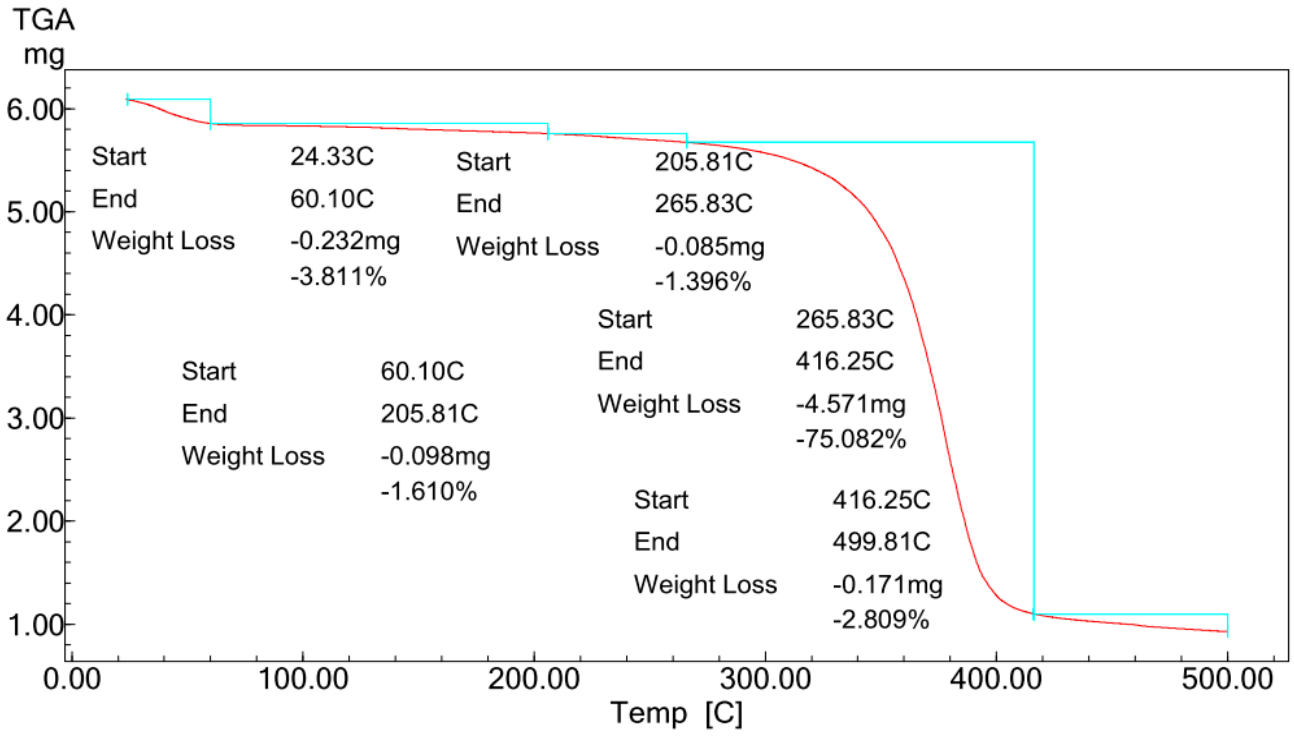

(B)

Figure 5. TGA profiles of $\mathrm{ZnO}$ polymeric nanofiber (A) before silver immobilization and (B) after silver immobilization.

Comparing the two patterns (Figure 5A,B) at this last thermal degradation step, it was indicated that the $\mathrm{ZnO}$ polymeric composite nanofibers matrix after $\mathrm{Ag}$ surface immobilization increases the thermal degradation to start at $416{ }^{\circ} \mathrm{C}$ compared with $406{ }^{\circ} \mathrm{C}$ for $\mathrm{ZnO}$ polymeric composite nanofibers matrix before $\mathrm{Ag}$ immobilization. Furthermore, the matrix weight loss was decreased to its half value for the Ag immobilized matrix. The weight losses were decreased from $4.6 \%$ for the $\mathrm{ZnO}$ polymeric composite nanofiber matrix before Ag immobilization to only $2.8 \%$ for that after Ag immobilization. These results 
confirm the positive role of $\mathrm{Ag}$ in improving the thermal stability of the $\mathrm{ZnO}$ polymeric composite nanofibers matrix.

\subsection{Photocatalytic Characteristics of ZnO Polymeric Nanofibers for Malachite Green Dye Degradation}

The performance of the two prepared $\mathrm{ZnO}$ polymeric nanofibers before and after $\mathrm{Ag}$ immobilization on malachite green (MG) dye photocatalytic degradation was compared against the different studied processing parameters.

\subsubsection{Effect of Contact Time}

The effect of contact time for photocatalytic malachite green dye degradation as a function of contact time at the studied range between 0 and $120 \mathrm{~min}$ using $0.1 \mathrm{~g}$ from either $\mathrm{ZnO}$ polymeric nanofibers after or before $\mathrm{Ag}$ immobilization at room temperature is investigated in Figure 6.

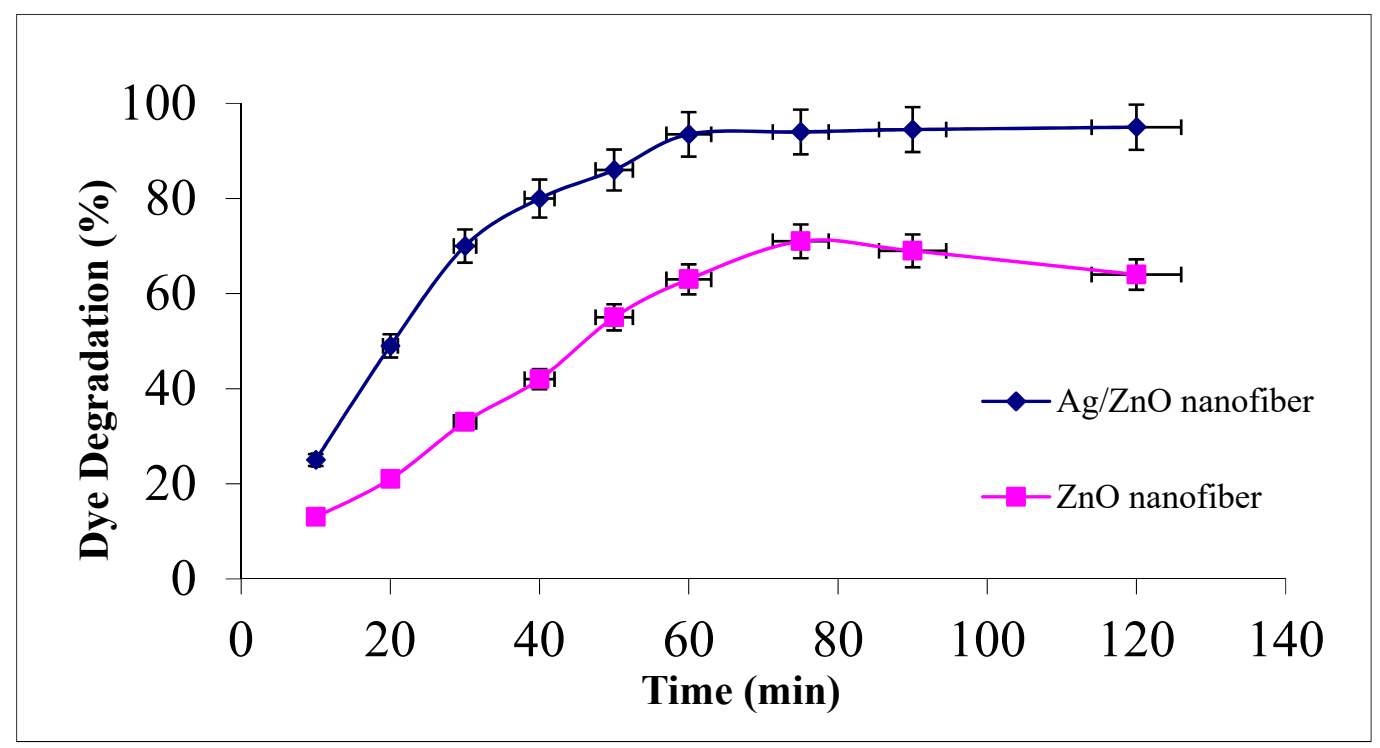

Figure 6. Effect of contact time on MG dye photocatalytic degradation process using ZnO polymeric nanofiber after and before silver immobilization (initial dye concentration $=20 \mathrm{ppm}$, nanofiber dose $=0.1 \mathrm{~g}, \mathrm{pH}=7$ at room temperature).

It was demonstrated that MG degradation activity increased with increasing contact time and reached its maximum value after $60 \mathrm{~min}$ for both studied nanofiber matrices. Comparing the photocatalytic degradation performance of the two nanofiber matrices after and before $\mathrm{Ag}$ immobilization, it was evident that the degradation efficiency was upgraded from $63 \%$ before $\mathrm{Ag}$ immobilization to $93.5 \%$ at 60 min after $\mathrm{Ag}$ immobilization. The degradation profiles for both nanofiber matrices showed a slight increment at the dye degradation performance after $60 \mathrm{~min}$ up to $120 \mathrm{~min}$, confirming that $60 \mathrm{~min}$ is suitable for completeness of the dye degradation process $[12,38]$.

\subsubsection{Effect of Malachite Green Dye Concentration}

The effect of malachite green dye concentration in the photocatalytic degradation process was studied by changing the initial dye concentration over the studied range of $10-120 \mathrm{ppm}$ to assess the appropriate dye concentration at a constant nanofiber dose of $0.1 \mathrm{~g}$ and agitation speed of $300 \mathrm{rpm}$ for $1 \mathrm{~h}$ at room temperature. It was indicated from Figure 7 that photocatalytic degradation efficiency decreased from 93.5 to $39 \%$ and 68 to $10 \%$ as the dye concentration increased from 10 to $120 \mathrm{ppm}$ for both $\mathrm{ZnO}$ polymeric nanofibers after and before silver immobilization, respectively. This behavior may be due to the increment in the initial dye concentrations which increases the availability of more dye molecules for excitation and energy transfer. This dependence is perhaps related to the formation 
of several monolayers of adsorbed dye onto both $\mathrm{ZnO}$ polymeric nanofibers after and before silver immobilization, which is favored at high dye concentrations. Until the critical level was reached, the surface was not completely covered, leading to constant reaction rates [39]. After this critical level, with a further increment in the initial dye concentration, a significant decline in the degradation efficiency with the increase in dye concentration occurs due to several reasons. As the initial concentrations of the dye increase more and more, dye molecules are adsorbed on the surface of the photocatalytic materials and a significant amount of $\mathrm{UV}$ is absorbed by the dye molecules rather than the $\mathrm{ZnO}$ polymeric nanofibers matrix. Hence, the penetration of light to the surface of the photocatalytic decreases hydroxyl radicals generation, which declines the dye degradation efficiency. Moreover, the adsorbed dye on the photocatalyst matrix inhibits the reaction of adsorbed molecules with the photo-induced positive holes or hydroxyl radicals, since there is no direct contact of $\mathrm{ZnO}$ semiconductor or even Ag metal with them. Accordingly, as the initial concentration of dye increases, the requirement of catalyst surface needed for the degradation should be increased to offer sufficient hydroxyl radicals attacking the available dye molecules for the complete dye degradation process [40].

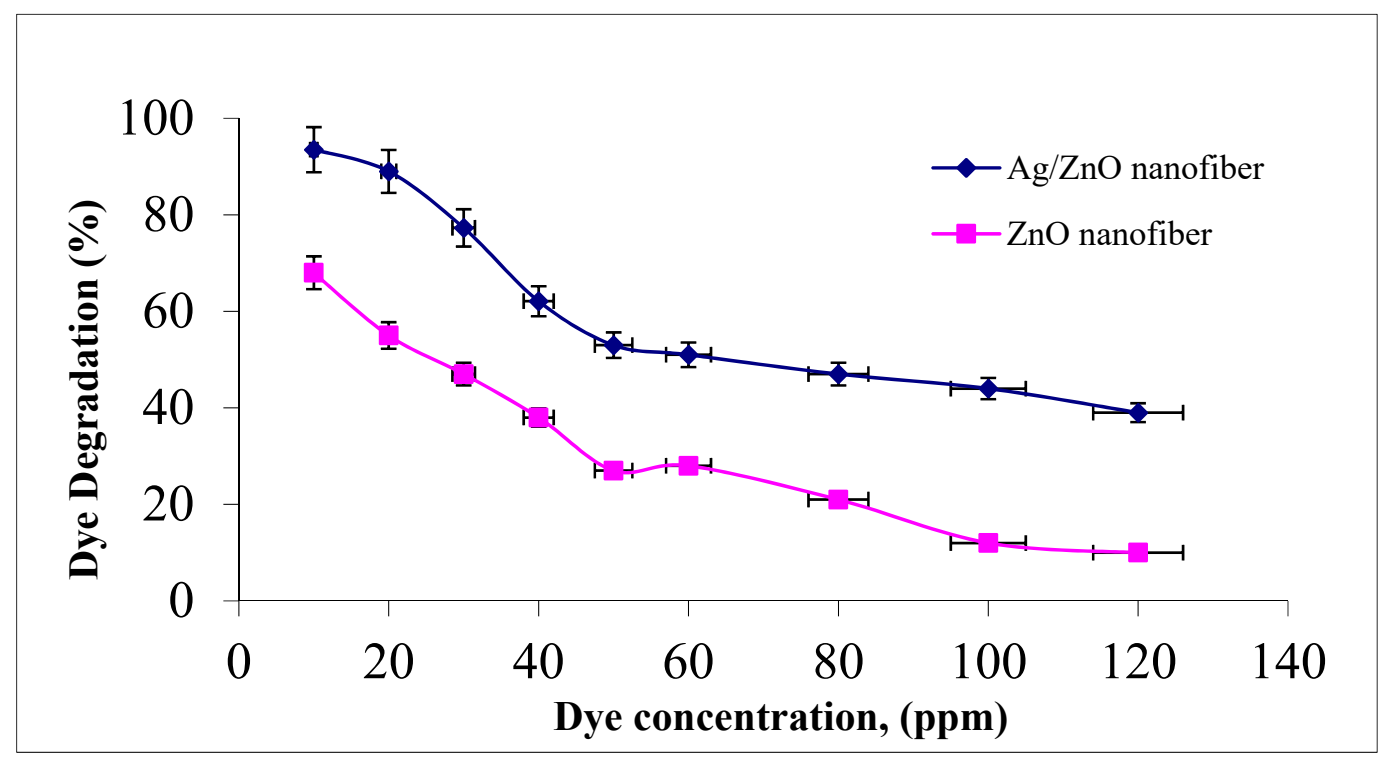

Figure 7. Effect of initial MG dye concentration on MG dye photocatalytic degradation process using ZnO polymeric nanofiber after and before silver immobilization (contact time $=60 \mathrm{~min}$, nanofiber dose $=0.1 \mathrm{~g}, \mathrm{pH}=7$ at room temperature).

\subsubsection{Effect of Polymeric Nanofiber Dosage}

The effect of polymeric nanofiber dosages on malachite green dye degradation over the studied range (0.05-0.25 g) after and before silver immobilization are compared in Figure 8. It was indicated that the two photocatalytic nanofibers were recorded at a maximum dye degradation efficiency when using $0.2 \mathrm{~g}$. However, as the nanofiber dosages increased above $0.2 \mathrm{~g}$, the dye degradation efficiency tend to decline. Therefore, the amount of photocatalytic studied nanofibers after and before Ag immobilization has both positive and negative impacts on the photodecomposition rate. In principle, the positive impact explained as the amount of catalyst is proportional to the number of active radicals like $\mathrm{OH} \bullet$ and $\mathrm{O}_{2} \bullet$ which rapidly degraded the adsorbed MG dye [41]. However, this regime may be due to the number of photocatalytic nanofibers which increased up to $0.2 \mathrm{~g}$, which increased the number of photons absorbed and consequently, the dye degradation rates increased. However, as the amount of nanofibers increases above $0.2 \mathrm{~g}$, this increases the solution opacity and leads to a decrease in the penetration of the photon flux in the reaction media and thereby decreases the dye photocatalytic degradation rate. Comparing the photocatalytic profiles of the two $\mathrm{ZnO}$ polymeric nanofibers before and after $\mathrm{Ag}$ 
immobilization, a high increment in dye degradation efficiency was recorded for nanofiber before $\mathrm{Ag}$ immobilization compared with that after $\mathrm{Ag}$ immobilization, as the nanofiber dosage increased from 0.1 to $0.2 \mathrm{~g}$. The dye degradation efficiency ranged from 55 to $96 \%$ compared with 93.5 to $97 \%$ as the nanofiber dosage improved from 0.01 to $0.2 \mathrm{~g}$ before and after Ag immobilization, respectively. These results confirm the dye degradation efficiency of $\mathrm{ZnO}$ polymeric nanofibers after Ag immobilization compared with the free one [42].

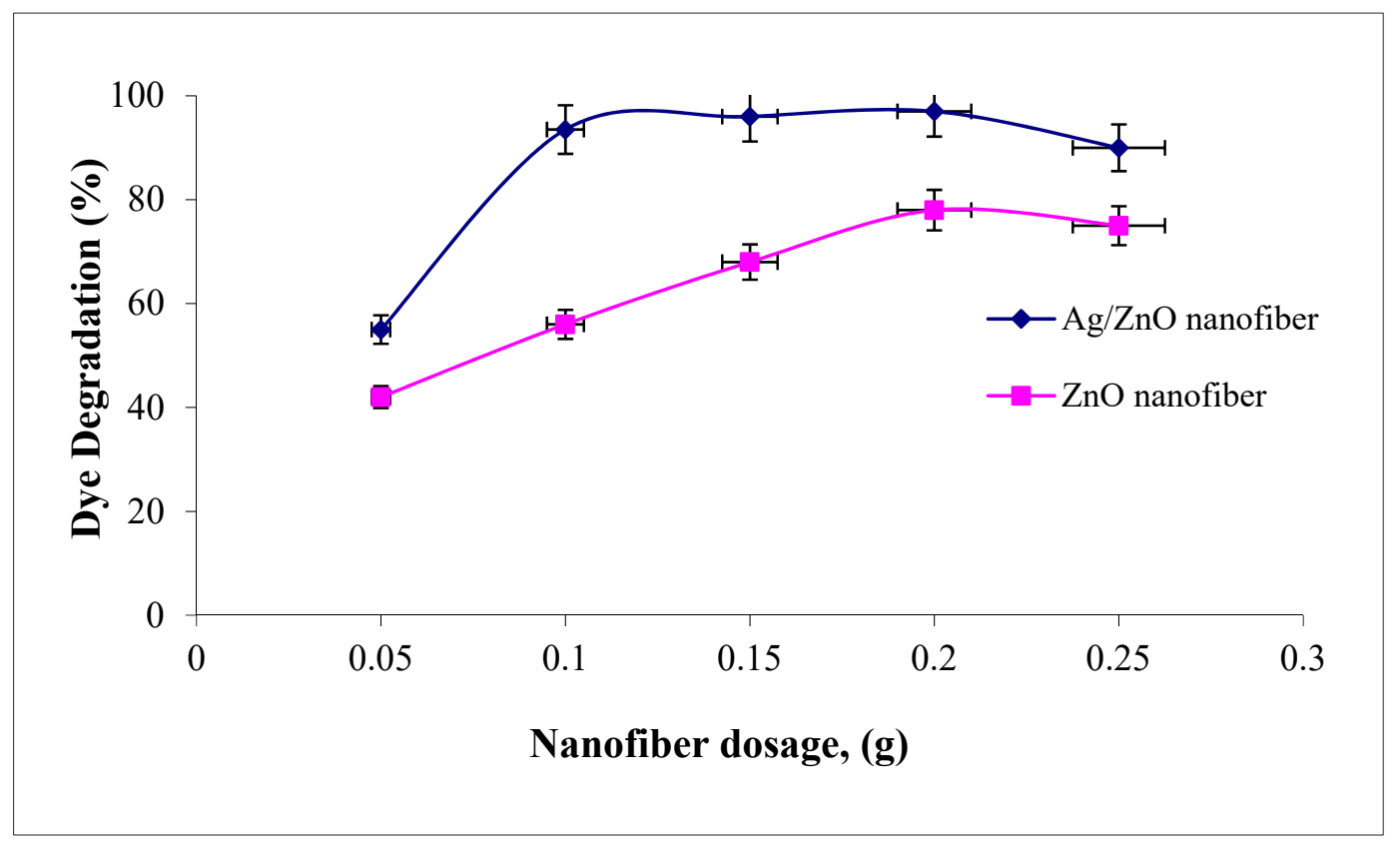

Figure 8. Effect of adsorbent dosage on the MG dye photocatalytic degradation process using ZnO polymeric nanofibers after and before silver immobilization (initial dye concentration $=20 \mathrm{ppm}, \mathrm{pH}=7$, contact time $=60$ min at room temperature)

\subsubsection{Effect of Solutions $\mathrm{pH}$}

The solution $\mathrm{pH}$ modifies the electrical double layer of the solid electrolyte interface and consequently affects the sorption-desorption processes and the separation of the photogenerated electron-hole pairs in the surface of the semiconductor particles. Accordingly, the influence of different solution $\mathrm{pH}$ values ranged from 2 to 12 as the degradation efficiency of MG dye was investigated on $\mathrm{ZnO}$ polymeric nanofibers after and before silver immobilization, as shown in Figure 9. It was observed that the degradation efficiency of MG was increased with an increase in solution $\mathrm{pH}$ for the two studied $\mathrm{ZnO}$ polymeric nanofibers after and before silver immobilization. The probable reason for this behavior may be explained due to the increase of the electrostatic adsorption of cationic MG dye on the $\mathrm{ZnO}$ polymeric catalyst surface that dependent on its surface charge [43]. As the point of zero charges (z.p.c) of $\mathrm{ZnO}$ is equal to 6.4, so at $\mathrm{pH}<\mathrm{pH}$ (z.p.c), the $\mathrm{ZnO}$ surface is positively charged (at acidic $\mathrm{pH}$ ), which decreases the electrostatic attraction of cationic MG dye. Dissimilar at $\mathrm{pH}>\mathrm{pH}$ (z.p.c), the $\mathrm{ZnO}$ surface is negatively charged (at $\mathrm{pH}>6.4$ ), which increases the electrostatic interaction between the negatively charged $\mathrm{ZnO}$ polymeric nanofibers and MG cations and leads to strong adsorption with a correspondingly high rate of dye degradation [44]. 


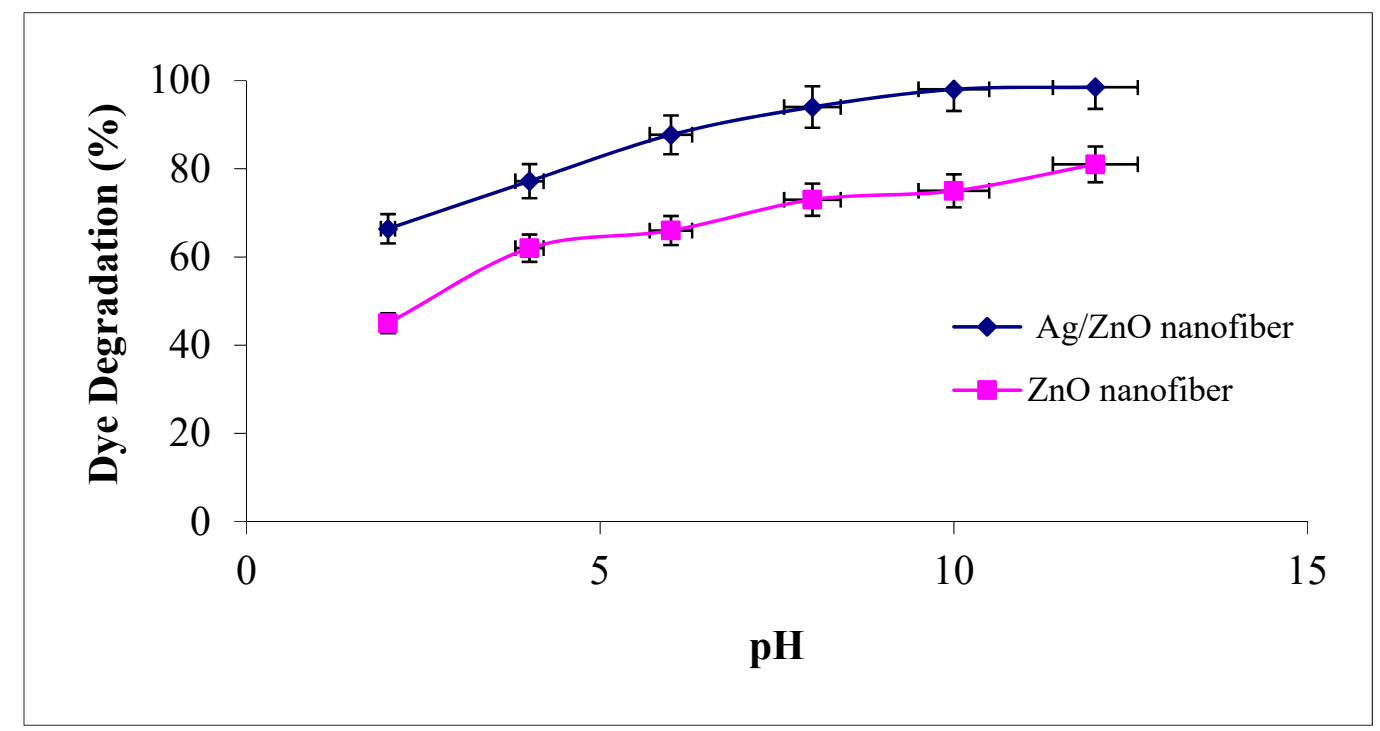

Figure 9. Effect of dye solution $\mathrm{pH}$ on the $\mathrm{MG}$ dye photocatalytic degradation process using $\mathrm{ZnO}$ polymeric nanofibers after and before silver immobilization (initial dye concentration $=20 \mathrm{ppm}$, nanofiberdose $=0.1 \mathrm{~g}$, contact time $=60 \mathrm{~min}$ at room temperature).

\subsubsection{Effect of Reaction Temperature}

The effect of photocatalytic reaction temperature studied ranged from 25 to $80^{\circ} \mathrm{C}$ on the degradation of malachite green dye using $\mathrm{ZnO}$ polymeric nanofibers after and before silver immobilization, as explained in Figure 10.

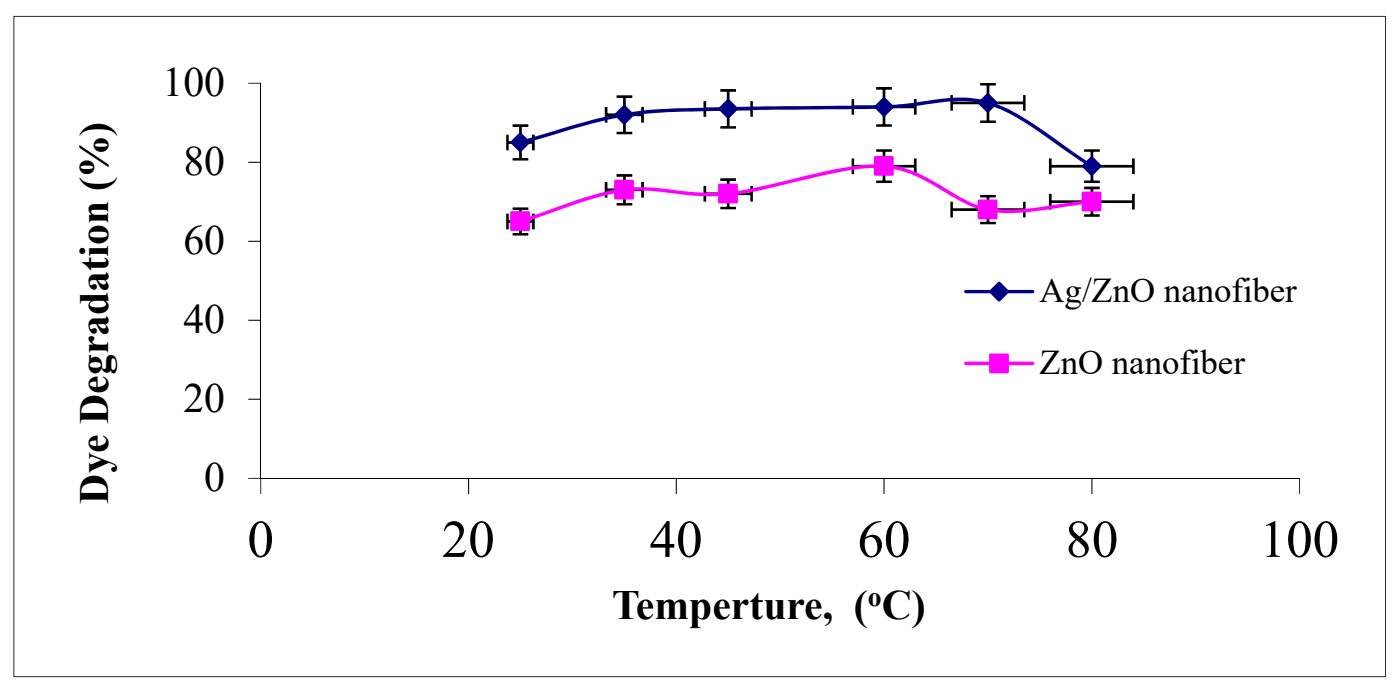

Figure 10. Effect of dye solution temperature on the MG dye photocatalytic degradation process using ZnO polymeric nanofibers after and before silver immobilization (initial dye concentration $=20 \mathrm{ppm}$, nanofiberdose $=0.1 \mathrm{~g}$, contact time $=60 \mathrm{~min}$ at $\mathrm{pH}=7$ ).

It was observed that the increase in the reaction temperature up to $50{ }^{\circ} \mathrm{C}$ resulted in an increase in the photodegradation efficiency of $\mathrm{MG}$ dye on the two $\mathrm{ZnO}$ polymeric nanofibers. This behavior may be returned to the increase in the reaction rate constant with increasing reaction temperature. On the contrary, as the reaction temperature increased above $50^{\circ} \mathrm{C}$ and tended to the boiling point of water, the photodegradation efficiency of MG dye on the two $\mathrm{ZnO}$ polymeric nanofibers tend to decline [45]. This may be returned to the exothermic nature of the adsorption process of the reactant. At elevated temperatures, 
the adsorption of the reactant MG dye, which is a spontaneous exothermic phenomenon, is disfavored. Besides, increasing the temperature also disfavors the adsorption of the final reaction product, whose desorption tends to inhibit the reaction. Therefore, the optimum range of operational temperatures was found to be in the range of $35-50{ }^{\circ} \mathrm{C}$ [46].

\subsection{Reusability of Fabricated $\mathrm{ZnO}$ Polymeric Composite Nanofibers}

Economically, the ability of the photocatalytic materials to be reused represents one of the paramount characteristics of efficient catalytic materials. Therefore, the reusability of both of the spent $\mathrm{ZnO}$ polymeric composite nanofibers before and after silver immobilization after the dye decolorization process was investigated using $\mathrm{HCl}$, and their ability for further reuse as photocatalytic membranes are represented in Figure 11. In order to confirm that the regenerated active sites at the regenerated $\mathrm{ZnO}$ polymeric composite membranes after and before silver immobilization have the ability for degrading MG dye molecules, the $\mathrm{HCl}$-regenerated nanofibers membranes were tested for 10 cycles as photocatalytic membranes. It was indicated from Figure 11 that the dye decolorization efficiency showed a minor decline for the regenerated $\mathrm{Ag} / \mathrm{ZnO}$ polymeric nanofibers from $97 \%$ (cycle 1) to $72 \%$ (cycle 10); they lost around 25\% from their initial efficiency. However, the regenerated $\mathrm{ZnO}$ polymeric nanofibers lost around $28 \%$ of their initial photocatalytic efficiency. This result may be due to incomplete desorption of MG dye from the surface of nanofibers when repeatedly used after regenerated with $\mathrm{HCl}$. Thus, this result confirms the efficient reusability and stability of prepared $\mathrm{ZnO}$ polymeric composite as photocatalytic membranes after its regeneration with $\mathrm{HCl}$ up to 10 cycles. Consequently, the fabricated $\mathrm{ZnO}$ polymeric nanofibers after and before Ag immobilization may be classified as economical and efficient photocatalytic membranes, which are crucial for industrial and large-scale practical applications.

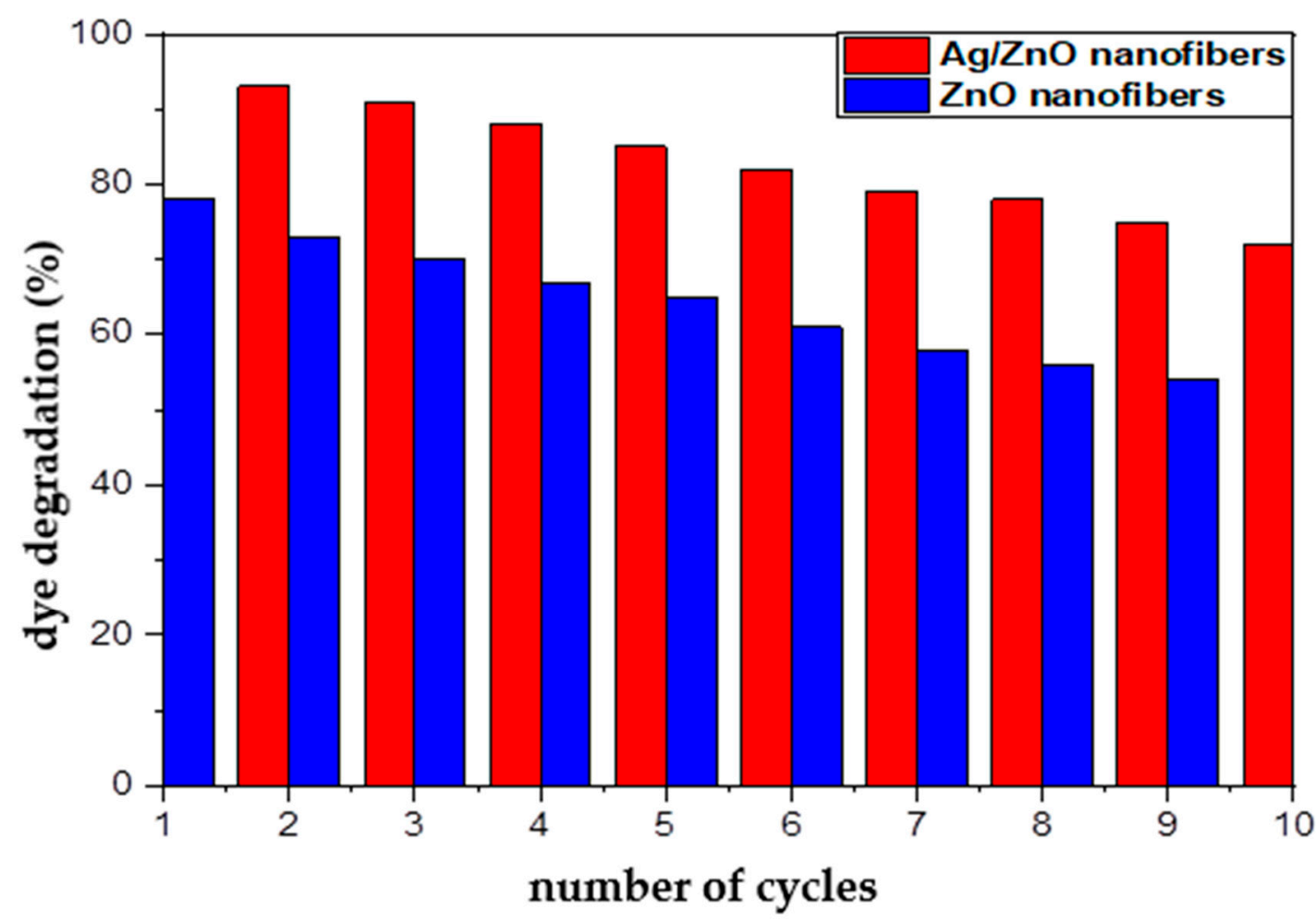

Figure 11. Reusability of $\mathrm{ZnO}$ polymeric composite nanofibers before and after silver immobilization as photocatalytic materials for MG dye decolorization process. 


\subsection{Suggested Mechanism of Malachite Green Dye Degradation Using ZnO Polymeric Nanofibers}

In general, photocatalytic degradation involves several steps such as adsorptiondesorption, electron-hole pair production and the recombination of the electron pair and chemical reaction. The suggested mechanism for photocatalytic degradation of organic molecules such as MG dye is explained in Figure 12.

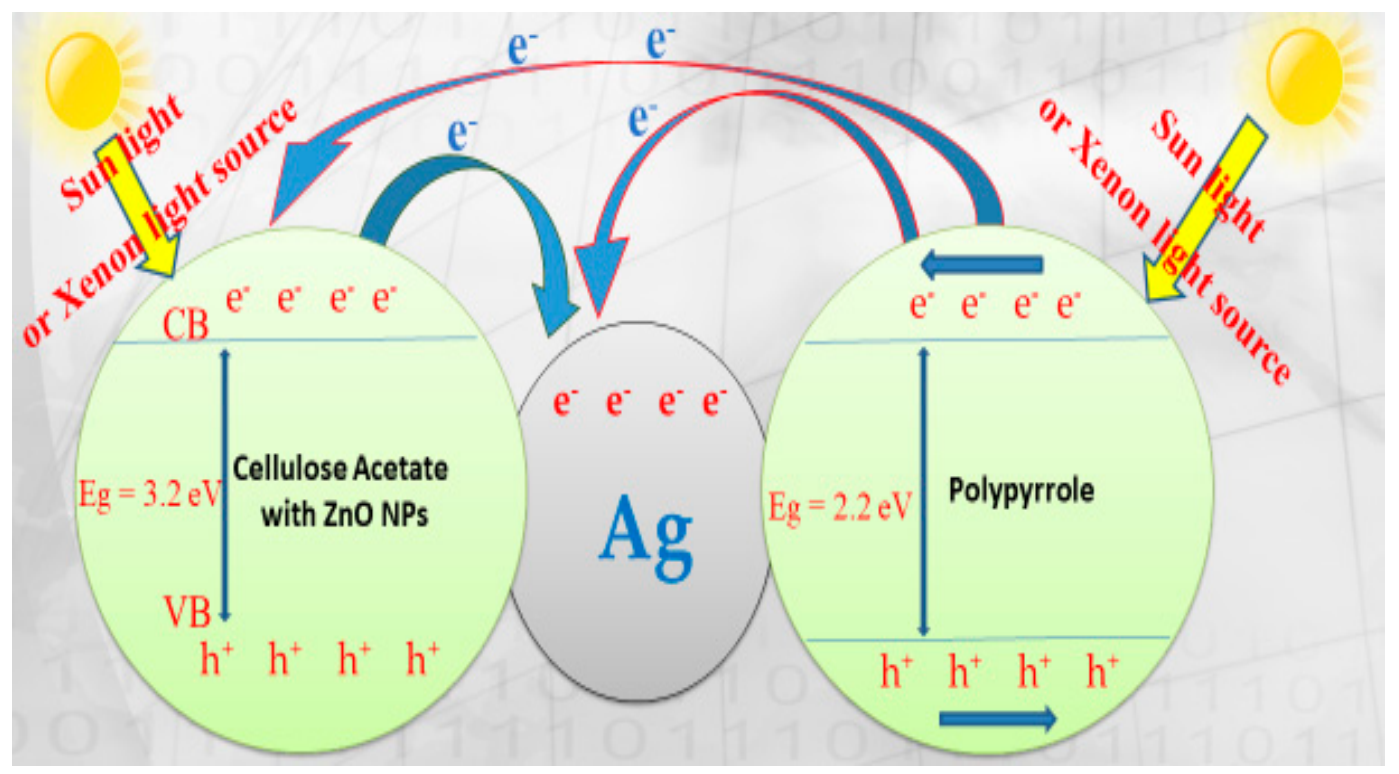

Figure 12. $\mathrm{OH}^{+}$Malachite green dye $\rightarrow$ products $\left(\mathrm{CO}_{2}\right.$ and $\left.\mathrm{H}_{2} \mathrm{O}\right)$. Scheme diagram of the photocatalytic degradation mechanism of malachite green dye (MG) on $\mathrm{ZnO}$ polymeric nanofiber immobilized with silver.

When $\mathrm{ZnO}$ polymeric nanofiber is irradiated with continuous photons energy similar to or more than the $\mathrm{ZnO}$ bandgap, the electrons $\left(\mathrm{e}^{-}\right)$are more excited and transferred from the $\mathrm{ZnO}$ polymeric catalyst valence band (VB) into the $\mathrm{ZnO}$ polymeric catalyst conduction band $(\mathrm{CB})$ with the spontaneous creation of holes $\left(\mathrm{h}^{+}\right)$in the valance band as follows:

$$
\mathrm{ZnO} \text { polymeric nanofiber photocatalyst }+\mathrm{hv} \rightarrow \mathrm{e} \mathrm{CB}^{-}+\mathrm{h} \mathrm{VB}^{+}
$$

The substantial energy required to transfer the electrons from the VB into the $\mathrm{CB}$ is expressed with $\mathrm{hV}$. The electrons generated during the radiation can be easily trapped by $\mathrm{O} 2$ that is absorbed on the solved superoxide or the $\mathrm{ZnO}$ polymeric nanofiber photocatalyst surface to give radicals of superoxide $\left(\mathrm{O}_{2}{ }^{-}\right)$.

$$
\mathrm{e} \mathrm{CB}^{-}+\mathrm{O}_{2} \rightarrow \mathrm{O}_{2}^{-}
$$

Therefore, $\mathrm{O}_{2}{ }^{-}$could react with $\mathrm{H} 2 \mathrm{O}$ molecules to produce hydroperoxy radical $\left(\mathrm{HO}_{2}\right)$ and hydroxyl radical $(\mathrm{OH})$, which are strong oxidizing agents, to decompose the organic molecule of MG dye [47-50].

$$
\mathrm{O}_{2}{ }^{-}+\mathrm{H}_{2} \mathrm{O} \rightarrow \mathrm{HO}_{2} \cdot+\mathrm{OH}
$$

The photogenerated holes must be trapped by surface $\left(\mathrm{OH}\right.$ or $\left.\mathrm{H}_{2} \mathrm{O}\right)$ on the photocatalyst surface to give hydroxyl radicals $(\mathrm{OH})$ :

$$
\begin{gathered}
\mathrm{h} \mathrm{VB}^{+}+\mathrm{OH}^{-} \rightarrow \mathrm{OH}_{\cdot a d} \\
\mathrm{~h} \mathrm{VB}^{+}+\mathrm{H}_{2} \mathrm{O} \rightarrow \mathrm{OH}+\mathrm{H}^{+}
\end{gathered}
$$


The organic molecules of MG dyes will be oxidized and converted to $\mathrm{CO}_{2}$ and $\mathrm{H}_{2} \mathrm{O}$ according to the following equation:

$$
\mathrm{OH} \cdot+\text { organic molecules }(\mathrm{MG} \text { dye })+\mathrm{O}_{2} \rightarrow \text { products }\left(\mathrm{CO}_{2} \text { and } \mathrm{H}_{2} \mathrm{O}\right)
$$

Meanwhile, the recombination of the positive hole and electron could take place, which could reduce the photocatalytic activity of the prepared $\mathrm{ZnO}$ polymeric nanofiber. This limitation was solved through surface modification of $\mathrm{ZnO}$ polymeric nanofiber with nanosilver to act as electron sinks to avoid the recombination process.

$$
\mathrm{e} \mathrm{CB}^{-}+\mathrm{h} \mathrm{VB}^{+} \rightarrow \mathrm{PC}
$$

$\mathrm{ZnO}$ cannot absorb much of the sunlight directly due to its large bandgap of $3.37 \mathrm{eV}$, but colored organic MG dye adsorbed on its surface and acts as a photosensitive matrix. Besides, the inclusion of the polymeric matrix with semiconductor polypyrrole (PPy) polymer with the $\pi$-orbital, which possesses highest occupied molecular orbital (HOMO) in the combined system, found that the lowest unoccupied molecular orbital (LUMO) levels of the polymer were energetically higher than the conduction band edge of $\mathrm{ZnO}$ [47]. Therefore, the suggested electron transfer paths for MG dye degradation are illustrated in Figure 11. As a result, rapid-charge separation and slow-charge recombination may occur using silver immobilized $\mathrm{ZnO}$ nanofiber.

When the $\mathrm{ZnO}$ polymeric composite nanofibers were illuminated under visible light, their electrons can be excited from the HOMO to the LUMO at the polymeric matrix, whereas the holes were left at the HOMO of the polymer. The excited-state electrons can be readily injected into the $\mathrm{CB}$ of $\mathrm{ZnO}$, and then further injected into the $\mathrm{Ag}$ fermi level. The metallic Ag nanoparticles functioned as an electron sink to accept the photoinduced electrons from the excited semiconductor. Silver-immobilized $\mathrm{ZnO}$ nanofiber had a quicker charge separation and slower charge recombination process compared with $\mathrm{ZnO}$ polymer nanofiber before $\mathrm{Ag}$ immobilization and thus possess higher photocatalytic activity. Moreover, the presence of the PPy polymer may cover the surface of $\mathrm{ZnO}$ and form a relatively thick layer that hinders the injection of excited electrons from the outer PPy polymer layer to the inner $\mathrm{ZnO}$ layer. Consequently, $\mathrm{OH}$. radicals decreased and the photodecomposition of the target contamination was affected [51].

\section{Conclusions}

In this work, $0.05 \%$ nano-zinc oxide was impregnated as a filler onto composite polymeric membrane composed from semiconductor polypyrrole mixed with cellulose acetate to fabricate homogeneous and uniform nanofiber using electrospinning at a $0.2 \mathrm{~mL} / \mathrm{h}$ solution flow rate, applied voltage of $18 \mathrm{kV}$, polymer concentration of $16 \%$ and the distance between needle tip to the collector were set at $18 \mathrm{~cm}$. As an attempt to increase the photocatalytic efficiency, the surface of this fabricated nanofiber was modified through immobilization with a nanosilver. The photocatalytic efficiency of the two fabricated nanofibers before and after silver immobilization was compared for malachite green dye degradation. It was evident that the silver-immobilized nanofiber showed higher photocatalytic degradation efficiency compared with that before silver immobilization for all studied degradation processing parameters including dye concentration, photocatalysis dosage, solution $\mathrm{pH}$ and reaction temperature. Immobilized nanosilver acted as an electron sink to avoid electron recombination that enhances photocatalytic activity. It was indicated that the increment at both photocatalysis dosage and solution $\mathrm{pH}$ has a positive impact on the MG dye degradation efficiency. On the contrary, the increases in dye concentration and reaction temperature have a negative impact on MG dye degradation efficiency.

Author Contributions: M.F.E. and H.S.H. contributed to the design of experiments, explanation of data and writing of the manuscript. M.F.E. and H.S.H. were involved in all stages, including the conception of the idea, designing experiments, conducting measurements, explanation of data 
and characterization analysis. All authors have read and agreed to the published version of the manuscript.

Funding: This research received no external funding.

Institutional Review Board Statement: Not applicable.

Informed Consent Statement: Not applicable.

Data Availability Statement: Not applicable.

Acknowledgments: This paper is based upon work supported by Science, Technology \& Innovation Funding Authority (STDF) under Grant (30735).

Conflicts of Interest: The authors declare no conflict of interest.

\section{References}

1. Ananpattarachai, J.; Kajitvichyanukul, P.; Seraphin, S. Visible light absorption ability and photocatalytic oxidation activity of various interstitial $\mathrm{N}$-doped $\mathrm{TiO}_{2}$ prepared from different nitrogen dopants. J. Hazard. Mater. 2009, 168, 253-261. [CrossRef]

2. Elkady, M.F.; Hassan, H.S. Invention of Hollow Zirconium Tungesto-Vanadate at Nanotube Morphological Structure for Radionuclides and Heavy Metal Pollutants Decontamination from Aqueous Solutions. Nanoscale Res. Lett. 2015, 10, 1-6. [CrossRef]

3. Hassan, H.S.; Elkady, M.; Farghali, A.; Salem, A.M.; El-Hamid, A.A. Fabrication of novel magnetic zinc oxide cellulose acetate hybrid nanofiber to be utilized for phenol decontamination. J. Taiwan Inst. Chem. Eng. 2017, 78, 307-316. [CrossRef]

4. Chequer, F.; de Oliveira, G.; Ferraz, E.; Cardoso, J.; Zanoni, M.; de Oliveira, D.P. Textile Dyes: Dyeing Process and Environmental Impact. In Book Title Eco-Friendly Textile Dyeing and Finishing; Gunay, M., Ed.; IntechOpen Limited: London, UK, 2013; Volume 6, pp. 151-176.

5. Elkady, M.F.; Hassan, H.S.; Amer, W.A.; Salama, E.; Algarni, H.; Shaaban, E.R. Novel Magnetic Zinc Oxide Nanotubes for Phenol Adsorption: Mechanism Modeling. Materials 2017, 10, 1355. [CrossRef] [PubMed]

6. Glavič, P.; Lukman, R. Review of sustainability terms and their definitions. J. Clean. Prod. 2007, 15, 1875-1885. [CrossRef]

7. Elkady, M.; Hassan, H.S.; Hashim, A. Immobilization of Magnetic Nanoparticles onto Amine-Modified Nano-Silica Gel for Copper Ions Remediation. Materials 2016, 9, 460. [CrossRef]

8. Hassan, H.S.; Kashyout, A.; Morsi, I.; Nasser, A.; Abuklill, H. Development of polypyrrole coated copper nanowires for gas sensor application. Sens. Bio-Sens. Res. 2015, 5, 50-54. [CrossRef]

9. Sharma, S.; Kaur, A. Various methods for removal of dyes from industrial effluents: A review. Indian J. Sci. Technol. 2018, 11, 1-21. [CrossRef]

10. Kamat, P. Manipulation of charge transfer across semiconductor interface a criterion that cannot be ignored in photo catalyst design. J. Phys. Chem. Lett. 2012, 3, 663-672. [CrossRef]

11. Hammad, A.; Haitham, M.; El-Bery, H.M.; EL-Shazly, A.H.; Elkady, M. Effect of $\mathrm{WO}_{3}$ Morphological Structure on its Photoelectrochemical Properties. Int. J. Electrochem. Sci. 2018, 13, 362-372. [CrossRef]

12. Bansal, P.; Bhullar, N.; Sud, D. Studies on photodegradation of malachite green using $\mathrm{TiO}_{2} / \mathrm{ZnO}$ photocatalyst. Desalin. Water Treat. 2009, 12, 108-113. [CrossRef]

13. Hammad, A.; Akihiko, A.; Xing, Z.; Akira, Y.; Daiki, O.; Teppei, Y.; EL-Shazly, A.; Elkady, M.; Hisao, Y. Photodeposition conditions of silver cocatalyst on titanium oxide photocatalyst directing product selectivity in photocatalytic reduction of carbon dioxide with water. Catal. Lett. 2020, 150, 1081-1088. [CrossRef]

14. Oualid, H.; Mahdi, C.; Emmanuel, N. Ultrasound-assisted removal of malachite green from aqueous solution by dead pine needles. J. Ultrason. Sonochem. 2008, 15, 799-807.

15. Frontistis, Z.; Hapeshi, E.; Fatta-Kassinos, D.; Mantzavinos, D. Ultraviolet-activated persulfate oxidation of methyl orange: A comparison between artificial neural networks and factorial design for process modelling. Photochem. Photobiol. Sci. 2015, 14, 528-535. [CrossRef]

16. El-Aassar, M.; El-Kady, M.; Hassan, H.S.; Al-Deyab, S.S. Synthesis and characterization of surface modified electrospun poly (acrylonitrile-co-styrene) nanofibers for dye decolorization. J. Taiwan Inst. Chem. Eng. 2016, 58, 274-282. [CrossRef]

17. Deitzel, J.; Kleinmeyer, J.; Harris, D.; Beck, N. The effect of processing variables on the morphology of electrospun nanofi-bers and textiles. J. Polymer. 2001, 42, 261-272. [CrossRef]

18. Shokry, H.; Elkady, M.; Salama, E. Eco-friendly magnetic activated carbon nano-hybrid for facile oil spills separation. Sci. Rep. 2020, 10, 1-17. [CrossRef]

19. Mohy-Eldin, M.S.; Elkady, M.F.; Abu-Saied, M.A.; Rahman, A.M.A.; Soliman, E.A.; Elzatahry, A.A.; Youssef, M.E. Removal of cadmium ions from synthetic aqueous solutions with a novel nanosulfonated poly(glycidyl methacrylate) cation exchanger: Kinetic and equilibrium studies. J. Appl. Polym. Sci. 2010, 118, 3111-3122. [CrossRef]

20. Ebrahimiasl, S.; Zakaria, A.; Kassim, A.; Basri, S.N. Novel conductive polypyrrole/zinc oxide/chitosan bionanocomposite: Synthesis, characterization, antioxidant, and antibacterial activities. Int. J. Nanomed. 2014, 10, 217-227. [CrossRef]

21. Saddeek, Y.; Shokry Hassan, H.; Abd Elfadeel, G. F Fabrication and analysis of new bismuth borate glasses containing cement kiln dust. J. Non-Cryst. Solids 2014, 403, 47-52. [CrossRef] 
22. Phiriyawirut, M.; Phaechamud, T. Gallic acid-loaded cellulose acetate electrospun nanofibers: Thermal properties, mechanical properties and drug release behavior. J. Polym. Chem. 2012, 2, 1-29. [CrossRef]

23. Zhang, H.; Zong, R.; Zhao, J.; Zhu, Y. Dramatic Visible Photocatalytic Degradation Performances Due to Synergetic Effect of TiO2with PANI. Environ. Sci. Technol. 2008, 42, 3803-3807. [CrossRef]

24. Tripathy, N.; Ahmad, R.; Kuk, H.; Lee, D.H.; Hahn, Y.-B.; Khang, G. Rapid methyl orange degradation using porous ZnO spheres photocatalyst. J. Photochem. Photobiol. B Biol. 2016, 161, 312-317. [CrossRef]

25. Elkady, M.F.; Hassan, H.S.; Salama, E. Sorption Profile of Phosphorus Ions onto ZnO Nanorods Synthesized via Sonic Technique. J. Eng. 2016, 2016, 1-9. [CrossRef]

26. Ma, S.; Li, R.; Lv, C.; Xu, W.; Gou, X. Facile synthesis of ZnO nanorod arrays and hierarchical nanostructures for photo-catalysis and gas sensor applications. J. Hazard. Mater. 2011, 192, 730-740. [CrossRef]

27. Tijing, L.; Amarjargal, A.; Jiang, Z.; Ruelo, M.; Park, C.; Pant, H.; Kim, D.; Lee, D.; Kim, C. Antibacterial tourmaline nanoparticles/polyurethane hybrid mat decorated with silver nanoparticles prepared by electrospinning and UV photo reduction. Curr. Appl. Phys. 2013, 13, 205-210. [CrossRef]

28. Fathona, I.; Yabuki, A. A simple one-step fabrication of Short polymer nano-fibers via electrospinning. J. Mater. Sci. 2014, 49, 3519-3528. [CrossRef]

29. Megelski, S.; Stephens, J.S.; Chase, A.D.B.; Rabolt, J.F. Micro- and Nanostructured Surface Morphology on Electrospun Polymer Fibers. Macromolecules 2002, 35, 8456-8466. [CrossRef]

30. Buchko, C.; Loui, C.; Shen, Y.; David, C. Processing and microstructural characterization of porous biocompatible protein polymer thin films. J. Polym. 1999, 40, 7397-7407. [CrossRef]

31. Viet, T.; The, C.; Tri, P.; Tien, P.; Manh, L. Synergistic Adsorption and Photocatalytic Activity under Visible Irradiation Using Ag-ZnO/GO Nanoparticles Derived at Low Temperature. J. Chem. 2019, 2019, 1-13.

32. Elkady, M.F.; Shokry Hassan, H.; El-Sayed, E.M. Basic Violet Decolourization Using Alginate Immobilized Nanozir-conium Tungestovanadate Matrix as Cation Exchanger. J. Chem. 2015, 2015, 385741. [CrossRef]

33. Wang, J.; Wei, B.; Kang, F. facile synthesis of hierarchical conducting polypyrrole nano-structures via a reactive tem-plate of $\mathrm{MnO} 2$ and their application in super capacitors. RSC Adv. 2014, 4, 199-202. [CrossRef]

34. Guanggui, C.; Jianning, D.; Zhongqiang, Z.; Zhiyong, L.; Huasheng, P. Study on the preparation and multi properties of the polypyrrole films doped with different ions. Surf. Interface Anal. 2012, 44, 844-850. [CrossRef]

35. Samy, M.; Mossad, M.; El-Etriby, H.K. Synthesized nano titanium for methylene blue removal under various operational conditions. Desalin. Water Treat. 2019, 165, 374-381. [CrossRef]

36. Azizi, S.; Ahmad, M.; Hussein, M.; Ibrahim, N.; Namvar, F. Preparation and properties of poly(vinyl-alcohol)/chitosan blend bio-nanocomposites reinforced with cellulose nanocrystals/ZnO-Ag multifunctional nanosized filler. Int. J. Nanomed. 2014, 9 , 1909-1917. [CrossRef] [PubMed]

37. Ramalingam, V.; Rajaram, R.; PremKumar, C.; Santhanam, P.; Dhinesh, P.; Vinothkumar, S.; Kaleshkumar, K. Bio-synthesis of silver nanoparticles from deep sea bacterium Pseudomonas aeruginosa JQ989348 for antimicrobial, antibiofilm and cytotoxic activity. J. Basic Microbiol. 2014, 54, 928-936. [CrossRef]

38. Modwi, A.; Abbo, M.; Hassan, E.; Al-Duaij, O.; Houas, A. Adsorption kinetics and photocatalytic degradation of malachite green (MG) via Cu/ZnO nanocomposites. J. Environ. Chem. Eng. 2017, 5, 5954-5960. [CrossRef]

39. Hachem, C.; Bocquillon, F.; Zahraa, O.; Bouchy, M. Decolourization of textile industry wastewater by the photocatalytic degradation process. Dye. Pigment. 2001, 49, 117-125. [CrossRef]

40. Sohrabi, M.; Davallo, M.; Miri, M. Influence of operational parameters on eliminating azo dyes from wastewater by advanced oxidation technology. Int. J. Chem. Tech. Res. 2009, 1, 446-451.

41. Muruganandham, M.; Swaminathan, M. Photocatalytic decolourisation and degradation of reactive orange 4 by $\mathrm{TiO}_{2}-\mathrm{UV}$ process. Dyes Pigment. 2006, 68, 133-142. [CrossRef]

42. Zhang, T.; Oyama, T.; Horikoshi, S.; Hidaka, H.; Zhao, J.; Serpone, N. Photocatalyzed N-demethylation and degrada-tion of methylene blue in titania dispersions exposed to concentrated sunlight. Sol. Energy Mater. Sol. Cells. 2002, 73, 287-303. [CrossRef]

43. Diab, K.E.; Salama, E.; Hassan, H.S.; El-Moneim, A.A.; Elkady, M.F. Biocompatible MIP-202 Zr-MOF tunable sorbent for cost-effective decontamination of anionic and cationic pollutants from waste solutions. Sci. Rep. 2021, 11, 1-13. [CrossRef]

44. Gar Alalm, M.; Samy, M.; Ookawara, S.; Ohno, T. Immobilization of S- $\mathrm{TiO}_{2}$ on reusable aluminum plates by pol-ysiloxane for photocatalytic degradation of 2,4-dichlorophenol in water. J. Water Process. Eng. 2018, 26, 329-335. [CrossRef]

45. Hassan, H.S. Role of preparation technique in the morphological structures of innovative nano-cation exchange. J. Mater. Res. Technol. 2019, 8, 2854-2864. [CrossRef]

46. Elkady, M.F.; El-Aassar, M.R.; Hassan, H.S. Adsorption profile of basic dye onto novel fabricated carboxylated func-tionalized co-polymer nanofibers. Polymers 2016, 8, 177. [CrossRef]

47. Mahanna, H.; Azab, M. Adsorption of Reactive Red 195 dye from industrial wastewater by dried soybean leaves modified with acetic acid. Desalin. Water Treat. 2020, 178, 312-321. [CrossRef]

48. Penghui, S.; Shuiping, Y.; Xiaoguang, D.; Liming, Y.; Hui, S.; Lin, D.; Jiayu, T.; Lixia, Y.; Xubiao, L.; Shaobin, W. Potential Difference Driving Electron Transfer via Defective Carbon Nanotubes toward Selective Oxidation of Organic Micropollutant. Environ. Sci. Technol. 2020, 54, 8464-8472. 
49. Penghui, S.; Jiayu, T.; Feng, Y.; Xiaoguang, D.; Shanshan, G.; Wenxin, S.; Xubiao, L.; Fuyi, C.; Shenglian, L.; Shaobin, W. Identification and Regulation of Active Sites on Nanodiamonds: Establishing a Highly Efficient Catalytic System for Oxidation of Organic Contaminants. Adv. Funct. Mater. 2018, 28, 1705295-1705303.

50. Penghui, S.; Xiaoguang, D.; Jun, X.; Jiayu, T.; Wenxin, S.; Shanshan, G.; Mingjun, X.; Fuyi, C.; Shaobin, W. Heterogeneous activation of peroxymonosulfate by amorphous boron for degradation of bisphenol S. J. Hazard. Mater. 2017, 322, 532-539.

51. Samy, M.; Alalm, M.G.; Mossad, M. Utilization of iron sludge resulted from electro-coagulation in heterogeneous photo-Fenton process. Water Pr. Technol. 2020, 15, 1228-1237. [CrossRef] 